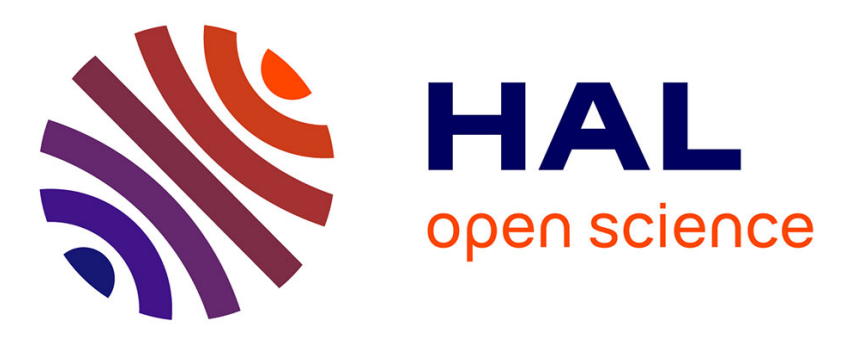

\title{
Thiophene-Bipyridine Appended Diketopyrrolopyrrole Ligands and Platinum(II) Complexes
}

\author{
Alexandre Abhervé, Maurizio Mastropasqua Talamo, Sara Boi, Vincent \\ Poupard, Frédéric Gendron, Boris Le Guennic, N. Avarvari, Flavia Pop
}

\section{- To cite this version:}

Alexandre Abhervé, Maurizio Mastropasqua Talamo, Sara Boi, Vincent Poupard, Frédéric Gendron, et al.. Thiophene-Bipyridine Appended Diketopyrrolopyrrole Ligands and Platinum(II) Complexes. Inorganic Chemistry, 2021, 60 (10), pp.7351-7363. 10.1021/acs.inorgchem.1c00534 . hal-03223879

\section{HAL Id: hal-03223879 \\ https://hal.science/hal-03223879}

Submitted on 13 Oct 2021

HAL is a multi-disciplinary open access archive for the deposit and dissemination of scientific research documents, whether they are published or not. The documents may come from teaching and research institutions in France or abroad, or from public or private research centers.
L'archive ouverte pluridisciplinaire HAL, est destinée au dépôt et à la diffusion de documents scientifiques de niveau recherche, publiés ou non, émanant des établissements d'enseignement et de recherche français ou étrangers, des laboratoires publics ou privés. 


\title{
Thiophene-bipyridine Appended Diketopyrrolopyrrole Ligands and Platinum(II) Complexes
}

\author{
Alexandre Abhervé, ${ }^{a}$ Maurizio Mastropasqua Talamo, ${ }^{a}$ Sara Boi, ${ }^{a}$ Vincent Poupard, ${ }^{a}$ Frédéric \\ Gendron, ${ }^{\mathrm{b}}$ Boris Le Guennic, ${ }^{\mathrm{b}}$ Narcis Avarvari, ${ }^{*, a}$ and Flavia Pop*,a \\ a MOLTECH-Anjou, UMR 6200, CNRS, UNIV Angers, 2 bd Lavoisier, 49045 ANGERS Cedex, France. E-mail: \\ narcis.avarvari@univ-angers.fr; flavia.pop@univ-angers.fr
}

b Univ Rennes, CNRS, ISCR (Institut des Sciences Chimiques de Rennes) - UMR 6226, F-35000 Rennes, France.

\begin{abstract}
Straightforward palladium (II) catalyzed direct cross-coupling reaction between decyl, (S)-2-methylbutyl and dodecyl N-substituted diketopyrrolopyrrole thiophene (DPPT), including a 3-methoxythiophene derivative, and 6-bromo-2,2'-bipyridine afforded a series of mono- and bis-bipyridine substituted DPPT ligands 1-3. Complexation reactions with $\mathrm{PtCl}_{2}(\mathrm{DMSO})_{2}$ provided ortho-metalated platinum (II) complexes 1-Pt and 2-Pt, together with the $\mathrm{N}^{\wedge} \mathrm{N}^{\wedge} \mathrm{O}$ complex $\mathbf{3 d - P t}\left(\mathbf{N}^{\wedge} \mathbf{N}^{\wedge} \mathrm{O}\right)$ resulted from the O-Me activation of the intermediary complex $\mathbf{3} \mathbf{d}-\mathbf{P t}\left(\mathbf{N}^{\wedge} \mathbf{N}\right)$. The ligand $\mathbf{1} \mathbf{b}$ and the mononuclear complexes $\mathbf{1 a - P t}$ and $\mathbf{1 b}$-Pt have been structurally characterized by single crystal X-ray structure, evidencing the establishment of numerous intermolecular $\pi-\pi$ interactions in the solid state. Moreover, in the crystal structure of the model complex DMTB-Pt( $\left.\mathbf{N}^{\wedge} \mathbf{N}^{\wedge} \mathbf{O}\right)$ (DMTB = 3,4-dimethoxy$\left(2,2^{\prime}\right.$-bipyridine)) the chelating tridentate $N^{\wedge} N^{\wedge} O$ mode is clearly evidenced. The chiral ligand $\mathbf{1 b}$ and its mononuclear complex $\mathbf{1 b}$-Pt do not show any CD signal in solution, but they are $C D$ active in the solid state, with bisignate bands in the low energy region, opposite in sign between the ligand and the complex, suggesting helical supramolecular arrangement of the dpp chromophore in the solid state. Photophysical investigations demonstrate that all the ligands are fluorescent, with high quantum yields, while the emission is quenched for the complexes, except partially in $\mathbf{3 d}-\mathbf{P t}\left(\mathbf{N}^{\wedge} \mathbf{N}\right)$, very likely through an intersystem crossing mechanism promoted by the heavy metal. DFT calculations support the differences observed between the absorption properties of the ligands, ortho- and non orthometalated complexes. The highly fluorescent bipyridine ligands reported herein open the way towards multifunctional transition metal complexes and their use in organic electronics.
\end{abstract}




\section{INTRODUCTION}

Diketopyrrolopyrrole (DPP) and its derivatives are very efficient fluorescence probes thanks to their high emission quantum yields and good stability. ${ }^{1}$ Therefore, they found applications in molecular imaging, ${ }^{2}$ DNA detection, ${ }^{3}$ anion/cation recognition, ${ }^{4}$ sensing, ${ }^{5}$ field effect transistors (FET), ${ }^{6}$ aggregation-induced emission (AIE), ${ }^{7}$ circularly polarized luminescence (CPL), ${ }^{8}$ or solar cells. ${ }^{9-11}$ They are usually prepared by reaction of an aromatic nitrile with dialkyl succinate, which allows to attach a large variety of aromatic groups on the DPP core, such as phenyl, ${ }^{12}$ pyridine, ${ }^{13}$ thiophene ${ }^{14,15}$ or selenophene. ${ }^{16}$ Although $\mathrm{Cu}(\mathrm{I}), \mathrm{Ag}(\mathrm{I})$ and $\mathrm{Au}(\mathrm{I})$ complexes of bis(deprotonated) dianionic DPP derivatives have been reported already in 2000 by Lorenz et al., ${ }^{17,18}$ the coordination and organometallic chemistry of DPP based ligands started to be more systematically explored in the last decade,$^{19}$ yet their number remains very limited to date. For example, derivatives of bis-2-thienyl-DPP (hereafter named DPPT) have been used to prepare metal-organic polymers ${ }^{20}$ or discrete coordination complexes with cobalt-dithiolene. ${ }^{21}$ The attachment of $\mathrm{N}$-donor subunits such as imines, within Schiff bases derived from $o$-salicylaldehyde attached to a thiophene of DPPT, ${ }^{22}$ or 2-pyridyl in combination with the deprotonated pyrrole $\mathrm{N}$ atoms to provide $N, N$ chelates, ${ }^{23-25}$ proved to be as well a valuable strategy to access DPP-based complexes. Finally, a last strategy consists of cross-coupling reactions between a DPPT derivative and a complex precursor (Chart 1). For example, Castellano et al. have reported Ir III complexes based on 2,2'-bipyridine (bpy) linked to DPPT through an alkyne linker. ${ }^{26,27}$ More recently, Schanze et al. have reported Pt" complexes containing the DPPT unit. The DPPT-Pt(acac) and the DPPT-Pt $(\mathrm{CC})$ complexes were prepared by cross-coupling reactions between the DPPT and the corresponding preformed Pt" complexes as building blocks. ${ }^{28,29}$ The particularity of the DPPT-Pt(acac) compound consists in the participation of the metal ion in ortho-metalation with the adjacent thiophene unit. Ortho-metalation of the pyridine and bpy adjacent rings (phenyl, thiophene) has been shown to be a straightforward strategy towards bis-, tris- and tetradentate chelated metal complexes that show interesting photophysical properties such as phosphorescence ${ }^{30-35}$ and excimer emission. ${ }^{36,37}$ Moreover, five member ring cyclometalated $\mathrm{Pt}^{\mathrm{t}}$ complexes have been also formed by $\mathrm{C}-\mathrm{H}$ activation of methoxy group of 6,6'-dimethoxy-bpy tridentate ligands. ${ }^{38}$

Chart 1. DPPT-based coordination complexes 


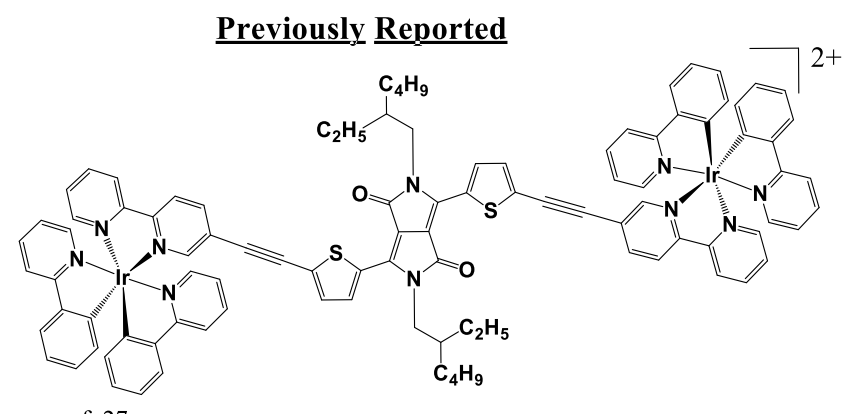

This Work

ref. 27

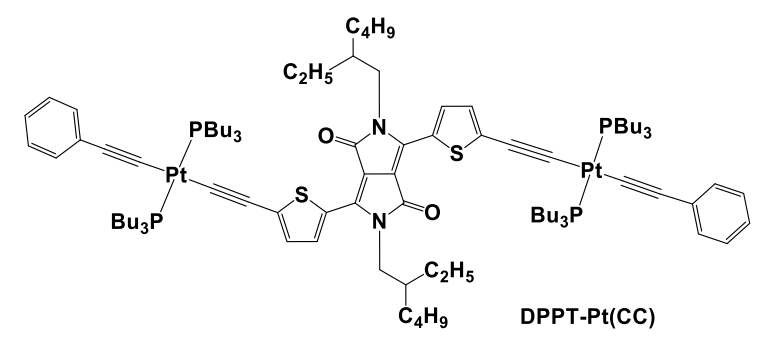

ref. 28
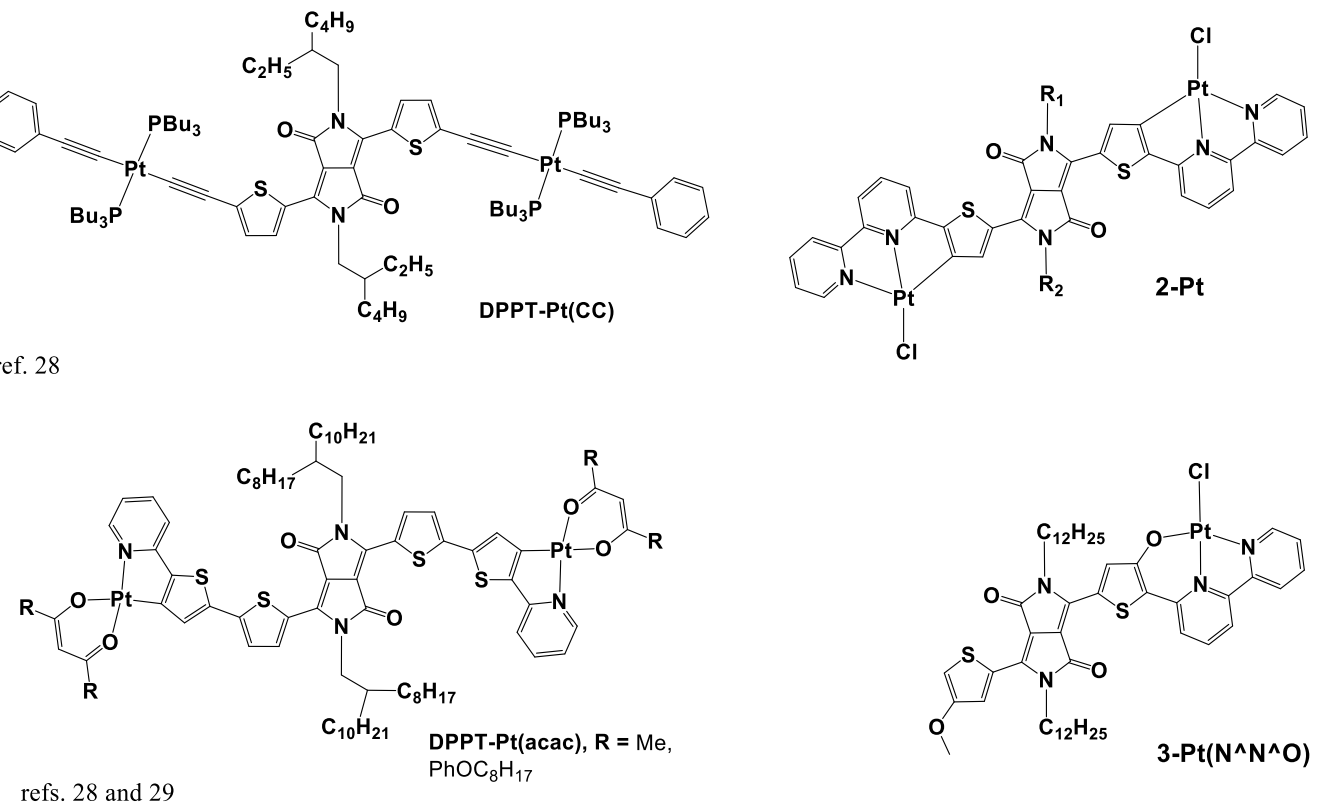

Here we propose unprecedented DPPT-2,2'-bpy ligands with direct link between thiophene and the chelating bpy units, which can afford, or not, ortho-metalation with platinum(II) depending on the substitution scheme of thiophene rings (Chart 1). Interestingly, ligands in which the position $3^{\prime}$ of the thiophene ring was blocked with methoxy units give, unexpectedly, unsymmetrical cyclometalated tridentate $\mathrm{N}^{\wedge} \mathrm{N}^{\wedge} \mathrm{O}$ chelated complexes with five $\left(\mathrm{N}^{\wedge} \mathrm{N}\right)$ and $\operatorname{six}\left(\mathrm{N}^{\wedge} \mathrm{O}\right)$ member rings. We describe herein the synthesis and characterization of ligands 1-3 (Scheme 1), their electrochemical and photophysical properties, backed up with DFT calculations. Coordination of Pt" metal ions, providing the mono- or bimetallic complexes 1-3-Pt, has been investigated with the objective to disclose the type of complexation of the heavy metal and its influence on the photophysical properties of the ligands. This represents the first such comparative study throughout a homogenous series of ortho-metalated Pt$\left(\mathrm{N}^{\wedge} \mathrm{N}^{\wedge} \mathrm{C}\right)$ and non ortho-metalated tridentate $\mathrm{Pt}-\left(\mathrm{N}^{\wedge} \mathrm{N}^{\wedge} \mathrm{O}\right)$ and bidentate $\mathrm{Pt}-\left(\mathrm{N}^{\wedge} \mathrm{N}\right)$ complexes prepared in a straightforward manner from common DPPT-bpy based ligands.

\section{RESULTS AND DISCUSSIONS}

\subsection{Synthesis and solid state structure characterization}

The DPPT-bpy based ligands (mono- and bis-chelating) and their corresponding mono- and binuclear complexes have been obtained following the synthetic sequence shown in Scheme 1 . The corresponding alkylated DPPT precursors (4 and $\mathbf{5}$ ) have been engaged in direct cross-coupling reactions ${ }^{39}$ under microwave conditions with 6-bromo-2,2'-bipyridine to afford ligands of type 1, 2 and 
3 in satisfactory yields by adjusting the amount of the bipyridine reagent. Two of the DPPT precursors, $\mathbf{4 b}$ and $\mathbf{4 c}$, are enantiomerically pure, being decorated with one and two chiral alkyl chains, respectively. The followed strategy in the case of DPPT 5 made use of methoxy units in order to block the 3-position of the two thiophene rings and thus to avoid the ortho-metalation. Then, by using the $\mathrm{Pt}^{\prime \prime} \mathrm{Cl}_{2}(\mathrm{DMSO})_{2}$ reagent four types of complexes have been obtained, i.e. three with tridentate binding mode (1-Pt, 2-Pt and $\left.\mathbf{3 d - P t}\left(\mathbf{N}^{\wedge} \mathbf{N}^{\wedge} \mathbf{O}\right)\right)$ and one with bidentate binding mode $\left(3 \mathbf{d}-\mathbf{P t}\left(\mathbf{N}^{\wedge} \mathbf{N}\right)\right)$. The completion of the complexation could be observed after one night by the color change of the reaction mixture from pink to deep blue for 1-Pt and 2-Pt. Mass spectrometry analysis and single crystal X-ray structure determination of compounds $\mathbf{1 a}-\mathbf{P t}$ and $\mathbf{1 b}$-Pt revealed the participation of the thiophene units in the coordination with the Pt(II) ion (vide infra). The ortho-metalation in compounds 1-Pt and 2-Pt was further confirmed by UV-Vis absorption measurements. Unexpectedly, coordination of ligand $3 \mathbf{d}$ to the $\mathrm{PtCl}_{2}$ fragment, aiming at obtaining the $\mathrm{N}^{\wedge} \mathrm{N}$ bidentate chelating mode within the $3 \mathbf{d}-\mathbf{P t}\left(\mathbf{N}^{\wedge} \mathbf{N}\right)$ complex, proved to be more complex than initially thought. Accordingly, ligand $\mathbf{3}$ was first reacted with one equivalent of $\mathrm{Pt}^{\prime \prime} \mathrm{Cl}_{2}(\mathrm{DMSO})_{2}$ reagent in dichloromethane at reflux. After 12 hours of reaction we have obtained a mixture of two complexes which, based on NMR spectroscopy and mass spectrometry, were the targeted $\mathbf{3} \mathbf{d}-\mathbf{P t}\left(\mathbf{N}^{\wedge} \mathbf{N}\right)$ together with $\mathbf{3} \mathbf{d}-\mathbf{P t}\left(\mathbf{N}^{\wedge} \mathbf{N}^{\wedge} \mathbf{O}\right)$ (Scheme 1), the latter resulting from the coordination of the thiophene-oxido form of the ligand following the unexpected O-Me cleavage. When a second equivalent of the $\mathrm{Pt}^{\prime \prime} \mathrm{Cl}_{2}$ (DMSO) $)_{2}$ reagent was added and the reaction continued for another 12 hours under reflux, complex $\mathbf{3 d}-\mathbf{P t}\left(\mathbf{N}^{\wedge} \mathbf{N}^{\wedge} \mathbf{O}\right)$ solely has been isolated. Thus, interestingly, complex $\mathbf{3 d - P t}\left(\mathbf{N}^{\wedge} \mathbf{N}^{\wedge} \mathbf{O}\right)$ has been obtained directly from the methoxy-thiophene-bipy ligand $\mathbf{3 d}$, upon in situ displacement of the methyl group of the adjacent methoxy substituent by $\mathrm{C}-\mathrm{O}$ activation promoted by a second equivalent of Pt(II) precursor. Consequently, while with ligand $\mathbf{3 d}$ orthometalation cannot take place as with ligands $\mathbf{1}$ and $\mathbf{2}$, in the obtained complex the ligand still shows a tridentate mode with the participation of the $\mathrm{O}$ atom of the thiophene, providing five $\left(\mathrm{N}^{\wedge} \mathrm{N}\right)$ and six $\left(\mathrm{N}^{\wedge} \mathrm{O}\right)$ member rings (Scheme 1 bottom and Scheme S1). Note that closely related $\mathrm{Pt}^{\left(\mathrm{N}^{\wedge} \mathrm{N}^{\wedge} \mathrm{O}\right)}$ complexes with phenoxo-2,2'-bipy ligands have been obtained stepwise from ortho-methoxy-phenyl$2,2^{\prime}$-bipy precursors upon deprotection of the methoxy group in acidic conditions followed by coordination of the resulting HO-phenyl-bipy ligands. ${ }^{40,41}$ In order to have a deeper insight on the reactivity of methoxy-thiophene-2,2'-bipy based ligands towards the $\mathrm{PtCl}_{2}(\mathrm{DMSO})_{2}$ precursor to afford $\mathrm{Pt}\left(\mathrm{N}^{\wedge} \mathrm{N}^{\wedge} \mathrm{O}\right)$ and/or $\mathrm{Pt}\left(\mathrm{N}^{\wedge} \mathrm{N}\right)$ complexes, we have designed the simplified model ligand 3,4-dimethoxythiophene-(2,2'-bipy) (DMTB) (Scheme S2, SI). Contrary to the synthesis of $\mathbf{3 d - P t}\left(\mathbf{N}^{\wedge} \mathbf{N}^{\wedge} \mathbf{O}\right)$ the test reaction has been directly performed with two equivalents of $\mathrm{Pt}^{\prime \prime} \mathrm{Cl}_{2}(\mathrm{DMSO})_{2}$ reagent, first at room temperature followed by reflux, each time for 12 hours. Interestingly, at room temperature, mass and exact mass spectrometry confirm the formation of the DMTB-Pt( $\left.\mathbf{N}^{\wedge} \mathbf{N}\right)$ complex only (see SI), whereas DMTB-Pt( $\left(\mathbf{N}^{\wedge} \mathbf{N}^{\wedge} \mathrm{O}\right)$ is obtained only after heating (see $\left.\mathrm{SI}\right)$. Chromatography separation afforded the pure tridentate complex. Single-crystal X-ray diffraction of DMTB-Pt( $\left(\mathbf{N}^{\wedge} \mathbf{N}^{\wedge} \mathbf{O}\right)$ unambiguously reveals the $\mathrm{N}^{\wedge} \mathrm{N}^{\wedge} \mathrm{O}$ tridentate binding mode of the ligand thanks to the elimination of the methyl group of methoxy adjacent to the bipy unit. This type of $\mathrm{C}-\mathrm{O}$ activation assisted by the vicinity of the $\mathrm{Cl}_{2} \mathrm{Pt}$ (bipy) fragment is unprecedented, to the best of our knowledge. Indeed, the presence of the coordinated

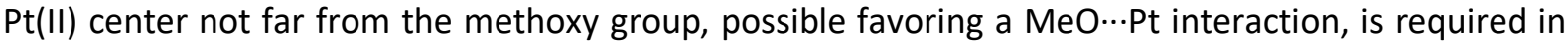
order to observe the cleavage of the O-Me bond. Accordingly, heating of $\mathrm{Pt}^{\prime \prime} \mathrm{Cl}_{2}(\mathrm{DMSO})_{2}$ with the simple 3,4-dimethoxy-thiophene precursor, not containing the 2,2'-bipy ligand, in the same conditions, does not provoke any $\mathrm{O}-\mathrm{Me}$ bond breaking. The exact mechanism of this unprecedented $\mathrm{C}-\mathrm{O}$ activation and the outcome of the leaving methyl group and of the second $\mathrm{Pt}(\mathrm{II})$ equivalent are unknown at the present stage. 
Scheme 1. Synthetic pathway for the preparation of compounds 1a-b, 2a-c (top) and 3d (bottom), together with their Pt complexes
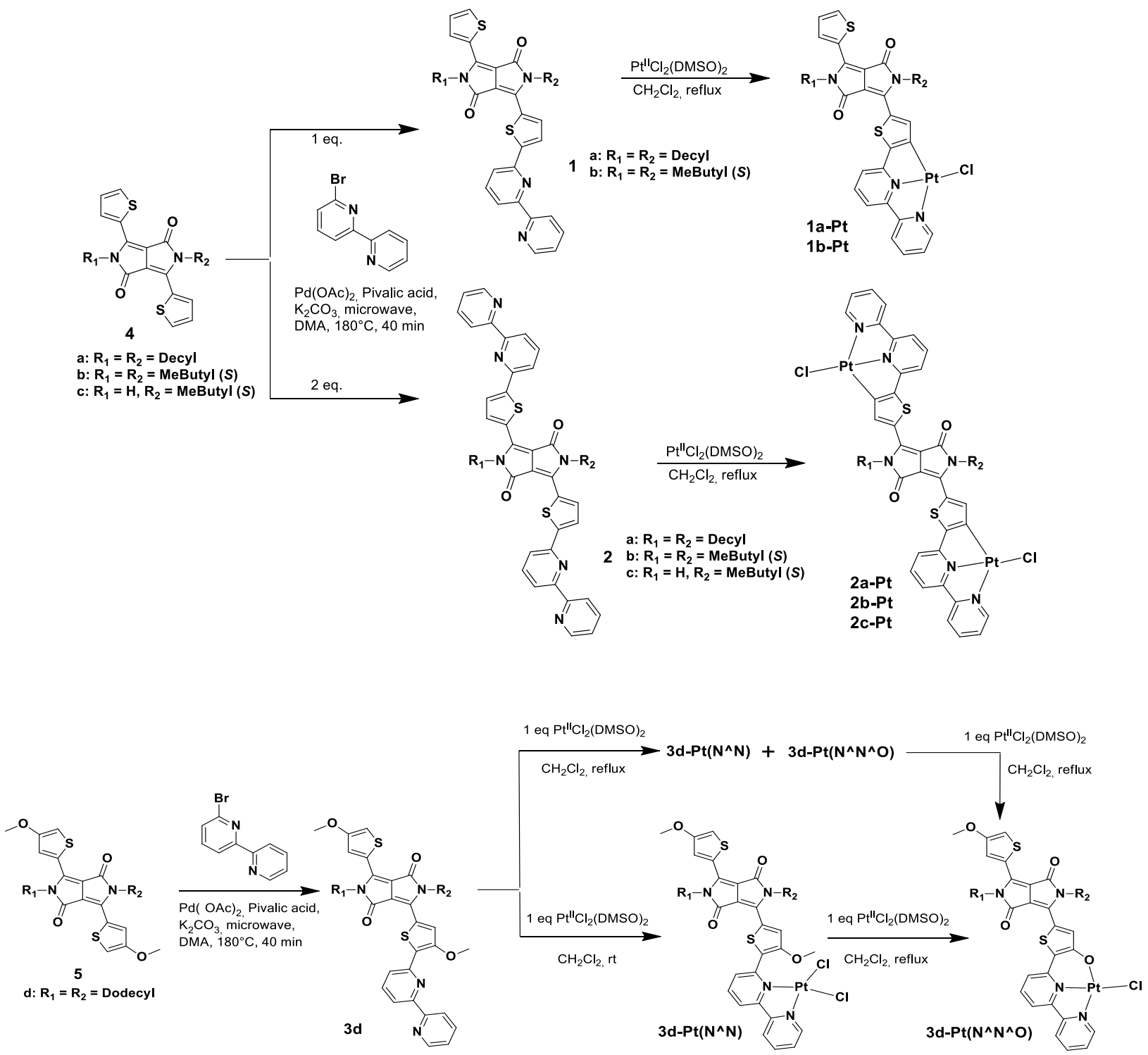

Single crystals of ligand $\mathbf{1 b}$ have been obtained by slow evaporation of a dimethylformamide (DMF) solution. The compound crystallizes in the monoclinic non-centrosymmetric $P 2_{1}$ space group, the asymmetric unit being composed of one independent molecule (Figure 1, Table S1). In both methylbutyl chains the stereogenic carbon atom preserves the $S$ configuration of the starting material, confirming that the molecule is enantiomerically pure. The thiophene rings are almost coplanar with the DPP unit, showing a small deviation from the DPP plane. The molecular planarity of the DPPT and their stacking along the crystallographic $a$ axis favor donor-acceptor intermolecular $\pi-\pi$ interactions between pyrrole and thiophene rings. Furthermore, C...S short distances of $4.26 \AA$ between the alkyl chain and the thiophene unit of the neighboring molecule have been observed (Figure 1). On the other hand, the bipyridine unit shows an important twist, with a dihedral angle of $26.25^{\circ}$ between the plane of the bipyridine and that of the DPPT core. As a consequence of the intermolecular $\mathrm{C}-\mathrm{H} \cdots \pi$ interactions between bipyridine and thiophene a helical arrangement of the molecules following the $b$ axis occurs (Figure 2). 

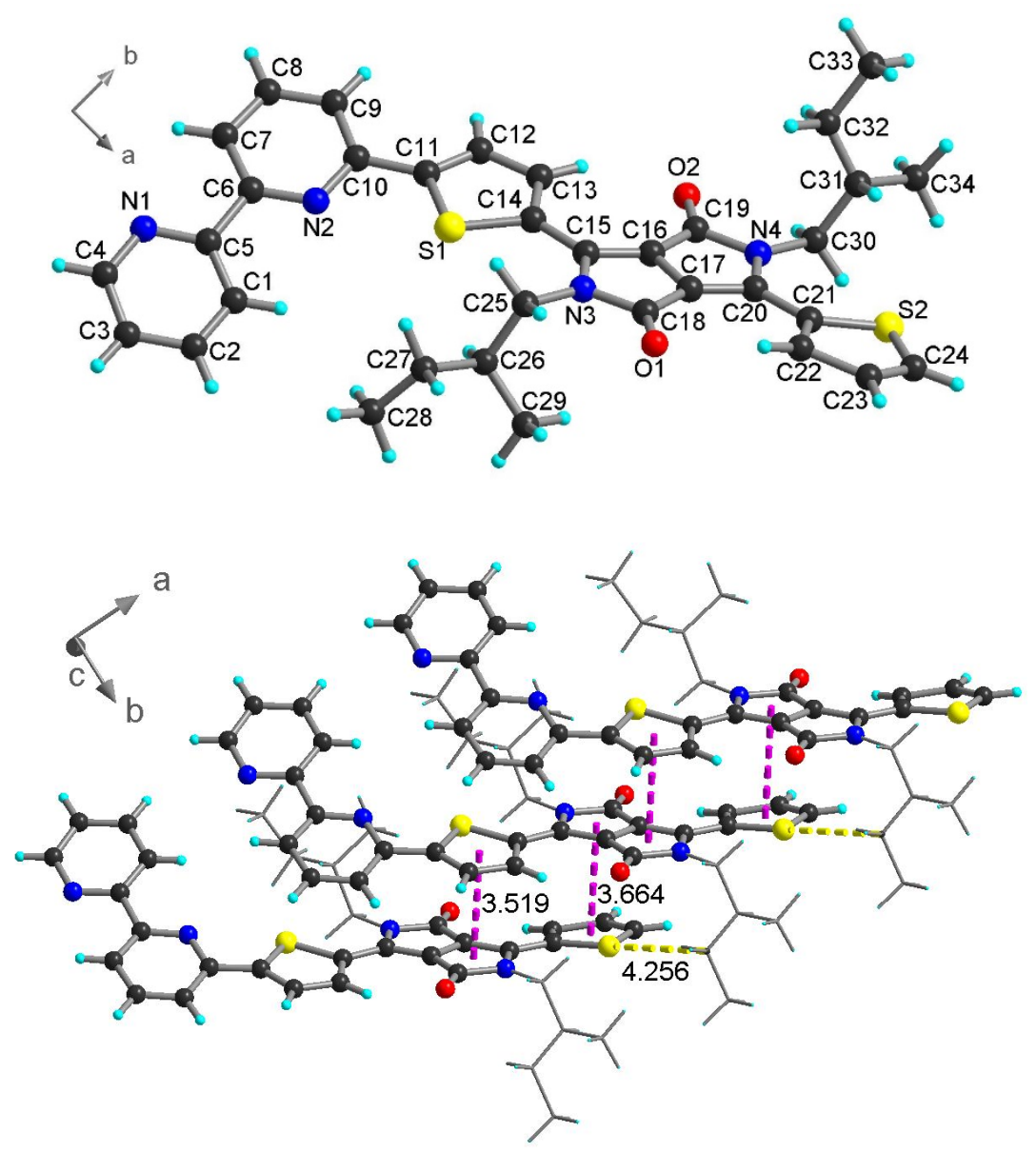

Figure 1. Structure of $\mathbf{1 b}$ with atom label (top). Intermolecular $\pi-\pi$ stacking (pink dashed lines) and $\mathrm{C}-\mathrm{H} \cdots \mathrm{S}$ interactions (yellow dashed lines). The 2-methyl-butyl chains are represented in a stick mode for clarity (bottom). Color code: C (black), H (cyan), N (blue), O (red), S (yellow). 


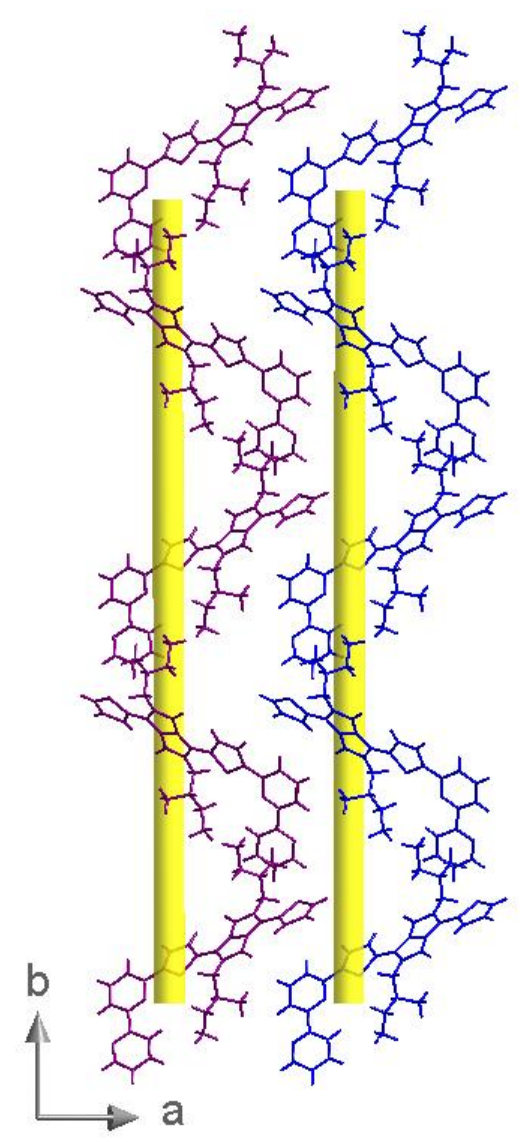

Figure 2. Helical arrangement of the molecules along the $b$ axis in $\mathbf{1} \mathbf{b}$.

Compound 1a-Pt could be obtained as dark platelet-like single crystals after recrystallization from a mixture of chloroform and DMF. The complex crystallizes in the monoclinic centrosymmetric $C 2 / c$ space group with one $[\mathrm{PtCl}(\mathbf{1 a})]$ molecule in the asymmetric unit (Figure $3 \mathrm{left}$, Table S1). One of the decyl $\left(C_{10}\right)$ alkyl chains is equivalently disordered over two positions. Similarly to the above described ligand, the thiophene rings show only a slow deviation from the planarity of the molecule (see Tables S2 and S3 for selected bond distances and torsion angles in $\mathbf{1 b}$ and $\mathbf{1 a - P t}$ ). In the complex, the bipyridine fragment is fixed by coordination with the platinum metal ion which renders coplanar all the aromatic units of the molecule. This planarity favors numerous intermolecular $\pi-\pi$ interactions between pyrrole, thiophene and bipyridine units, thus forming dimers of complexes in a head-to-tail fashion (Figure 4). However, these dimers are quite isolated from each other due to the presence of bulky $\mathrm{C}_{10}$ alkyl chains (Figure $\mathrm{S} 1$ ).

Compound 1 $\mathbf{b}$-Pt was obtained as dark needle-like single crystals. Due to the presence of chiral $S$ methyl-butyl chains on the lactam unit, this compound crystallizes in the non-centrosymmetric $P 1$ space group and presents a very different crystal packing (Figures S2 and S3, Table S1). Indeed chains of complexes are formed along the $a$ axis, following an -A-B-A-B- sequence (Figure 5). These chains can be described as dimers of complexes disposed in a similar head-to-tail arrangement and molecular overlap as in 1a-Pt with $\pi-\pi$ stacking (B-A contacts). These dimers are connected to each other via strong Pt-Pt interactions of $3.282 \AA$ ( $A-B$ contacts) which has as consequence a massive longitudinal shift of the successive dimers leading to less $\pi-\pi$ interactions when compared to the intra-dimer ones. 


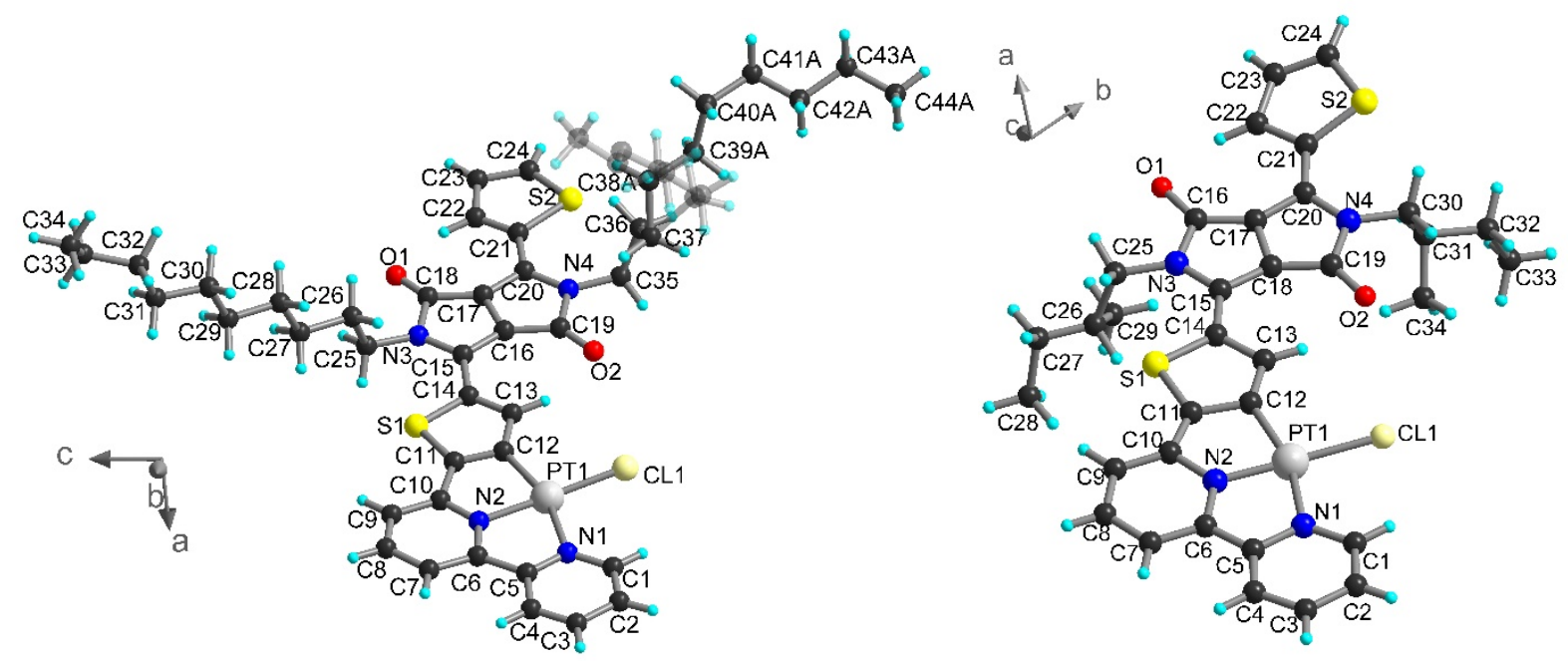

Figure 3. Structures of 1a-Pt (left) and 1b-Pt (right) with atom label. Color code: C (black), H (cyan), N (blue), O (red), S (yellow), Cl (light yellow), Pt (grey).

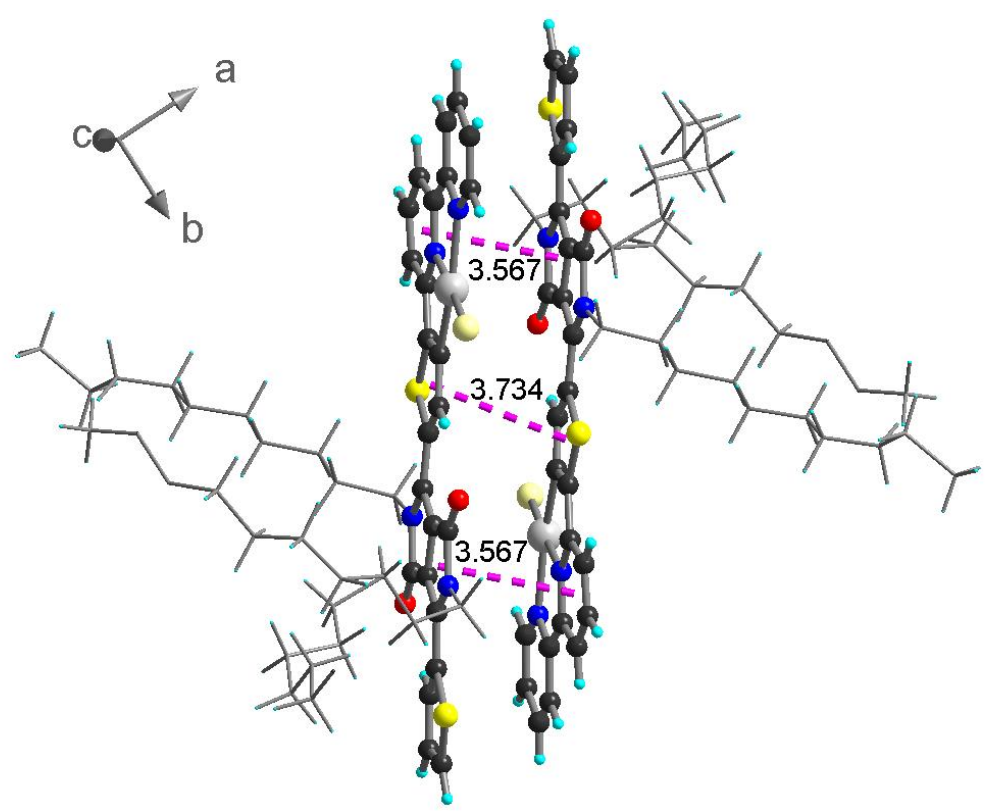

Figure 4. Intermolecular $\pi-\pi$ stacking (pink dashed lines) between neighboring molecules in 1a-Pt of $3.567 \AA$ and $3.734 \AA$ A). The $\mathrm{C}_{10}$ alkyl chains are represented in a stick mode for clarity. Color code: $\mathrm{C}$ (black), $\mathrm{H}$ (cyan), N (blue), $\mathrm{O}$ (red), S (yellow), Cl (light yellow), Pt (grey). 


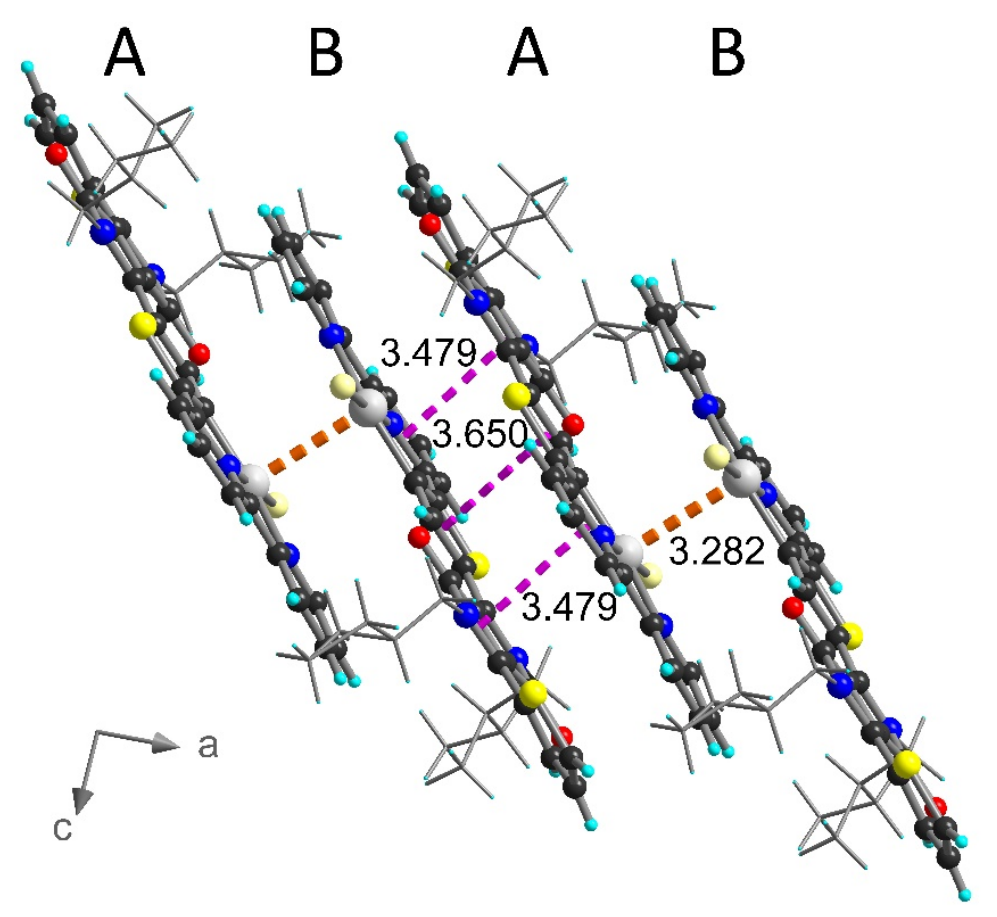

Figure 5. Intermolecular $\pi-\pi$ stacking (pink dashed lines) and Pt $\cdots$ Pt interactions (orange dashed lines) between neighbouring molecules in 1b-Pt of $3.479 \AA$, $3.650 \AA$ and $3.282 \AA$, respectively. The 2-methyl-butyl chains are represented in a stick mode for clarity. Colour code: C (black), H (cyan), N (blue), O (red), S (yellow), Cl (light yellow), Pt (grey).

Finally, the model complex DMTB-Pt(N^N^O) has been obtained as single crystals by slow evaporation of a dichloromethane solution. It crystallized in the monoclinic space group $P 2_{1} / \mathrm{c}$. The structure of the complex definitely confirms the elimination of the methyl group through the cleavage of the O-Me bond from one methoxy unit and thus the coordination of the platinum metal center in a $\mathrm{N}^{\wedge} \mathrm{N}^{\wedge} \mathrm{O}$ tridentate mode (Figure 6).

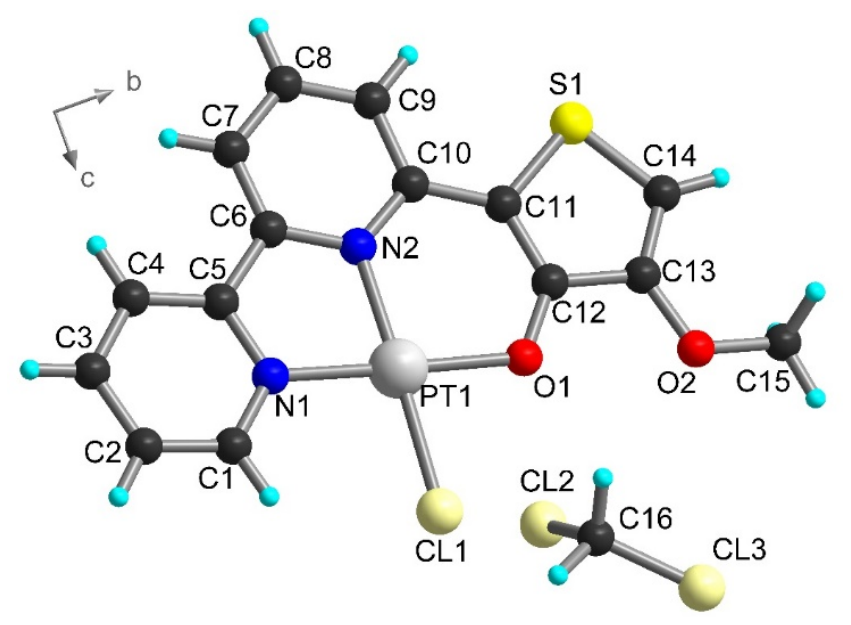

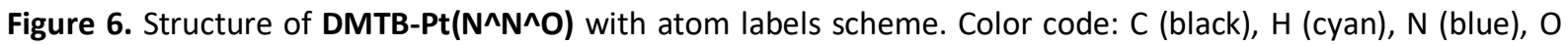
(red), S (yellow), Cl (light yellow), Pt (grey).

\subsection{Absorption and emission properties}


Compounds $\mathbf{1 a}$ and $\mathbf{1 b}$, bearing one bipy chelating unit, present a maximum of absorption around 580 $\mathrm{nm}$, which is about $40 \mathrm{~nm}$ bathochromically shifted compared to parent DPPT molecules (Figure 7). ${ }^{1}$ These bands are further red-shifted by $\mathbf{2 0 - 3 0 ~ n m ~ i n ~ c o m p o u n d s ~} \mathbf{2 a}, \mathbf{2} \mathbf{b}$ and $\mathbf{2 c}$, as a consequence of the increased $\pi$-conjugated system thanks to the presence of two bpy units (Table 1 ). Another way to modulate the HOMO-LUMO gap is by introducing strong electron-donating groups on the thiophene rings, as recently emphasized by Dudnik et al. in methoxy-substituted DPP polymers. ${ }^{42}$ Indeed, the maximum of absorption of compound $\mathbf{3 d}$, which bears a methoxy substituent in the position 3 of thiophene, presents a bathochromic shift compared to compounds $\mathbf{1 a}$ and $\mathbf{1 b}\left(\lambda_{\max }=594 \mathrm{~nm}\right)$. Both absorption and emission spectra show the typical dpp two-band pattern for all compounds due to a vibronic structure (vide infra). The quantum yields of all the ligands have been determined, showing values between $56-59 \%$ for $\mathbf{1}$ and $\mathbf{2}$, and $\mathbf{7 7 \%}$ for the methoxy-substituted $\mathbf{3 d}$, which are lower than in the parent DPPT compound (around $85 \%$ ). ${ }^{28}$
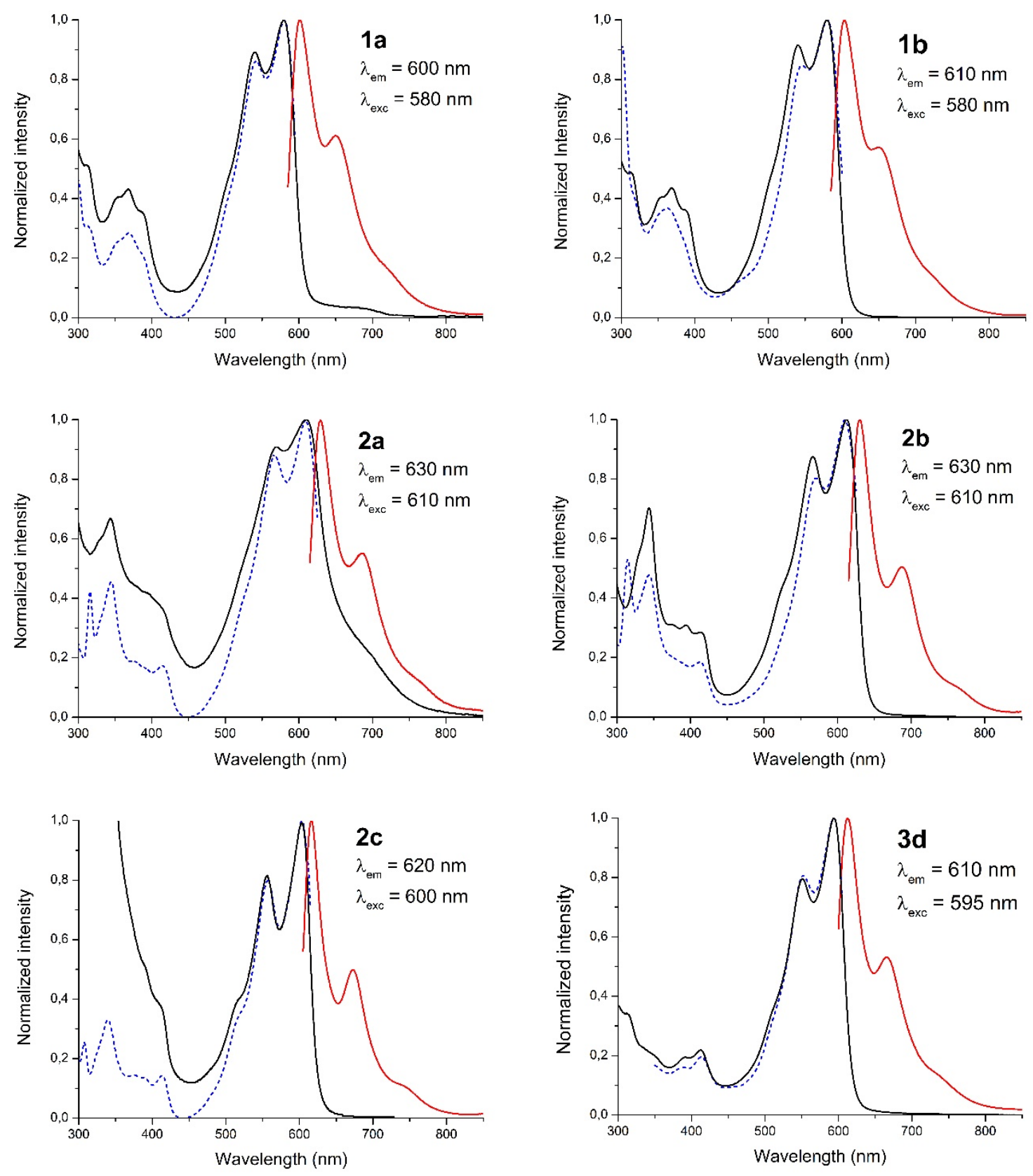
Figure 7. Normalized absorption (black), emission (red) and excitation spectra (dashed blue) of compounds 1-3 at room temperature in DCM solution (except of $\mathbf{2 c}$ recorded in THF solution). Incident excitation and emission wavelengths are noted.

Table 1. Values of maximum absorption and emission wavelengths, maximum molar extinction coefficients and quantum yield of luminescence for compounds 1-3

\begin{tabular}{|c|c|c|c|c|c|}
\hline \multirow{2}{*}{ Compound } & \multicolumn{4}{|c|}{ Absorption } & \multicolumn{2}{c|}{ Emission } \\
\cline { 2 - 6 } & $\boldsymbol{\lambda}_{\mathbf{1}}$ & $\boldsymbol{\lambda}_{\max }$ (nm) & $\begin{array}{c}\boldsymbol{\varepsilon}_{\max } \\
\left(\text { L.mol } \mathbf{~}^{-1} \cdot \mathrm{cm}^{-1}\right)\end{array}$ & $\boldsymbol{\lambda}_{\max }$ (nm) & $\begin{array}{c}\text { Quantum Yield } \\
\text { (\%) }\end{array}$ \\
\hline 1a & 540 & 580 & 41800 & 601 & 57 \\
\hline 1b & 540 & 580 & 37315 & 604 & 56 \\
\hline 2a & 569 & 609 & 38100 & 630 & 59 \\
\hline 2b & 566 & 611 & 34900 & 631 & 57 \\
\hline 2c & 558 & 605 & 35300 & 618 & 56 \\
\hline 3d & 551 & 594 & 45720 & 612 & 77 \\
\hline
\end{tabular}

In general the complexes show a bathochromic shift of their maximum of absorption after coordination by the Pt" metal ion (Figure 8). This shift is about $50-60 \mathrm{~nm}$ in the binuclear compounds 2-Pt, whereas in the mononuclear compounds 1-Pt, $\mathbf{3 d - P t}\left(\mathbf{N}^{\wedge} \mathbf{N}\right)$ and $\mathbf{3 d}-\mathbf{P t}\left(\mathbf{N}^{\wedge} \mathbf{N}^{\wedge} \mathbf{O}\right)$ it is only between 3 and $8 \mathrm{~nm}$. Compounds 1-Pt and 2-Pt show a broadening of the absorption band and an abrupt decrease of the molar extinction coefficient $\left(\varepsilon_{\max }\right)$ values after complexation (Figure S4). It should be noted that the decrease rate of the $\varepsilon_{\max }$ values is the same in either mononuclear or binuclear complexes (about four times lower compared to the related free ligand). On the contrary, the absorbance spectra of the nonortho-metalated complexes $\mathbf{3 d - P t}\left(\mathbf{N}^{\wedge} \mathbf{N}\right)$ and $\mathbf{3 d}-\mathbf{P t}\left(\mathbf{N}^{\wedge} \mathbf{N}^{\wedge} \mathbf{O}\right)$ are more similar in shape and intensity to that of the free ligand 3d. Regardless the complexation scheme (mono-or bi-nuclear and tridentate) the $\mathrm{Pt}^{\prime \prime}$ complexes lose the emissive properties due to an increase in non-radiative decay promoted by $\mathrm{S}_{1} \rightarrow \mathrm{T}_{1}$ intersystem crossing. ${ }^{43}$ While in the tridentate coordination modes the emission of the DPPT chromophore is completely quenched, the bidentate $3 \mathbf{d}-\mathbf{P t}\left(\mathbf{N}^{\wedge} \mathbf{N}\right)$ shows a residual fluorescence of the DPPT chromophore as deduced from the measured quantum yield of about $16 \%$. No phosphorescence could be observed for these complexes (Figure S5).

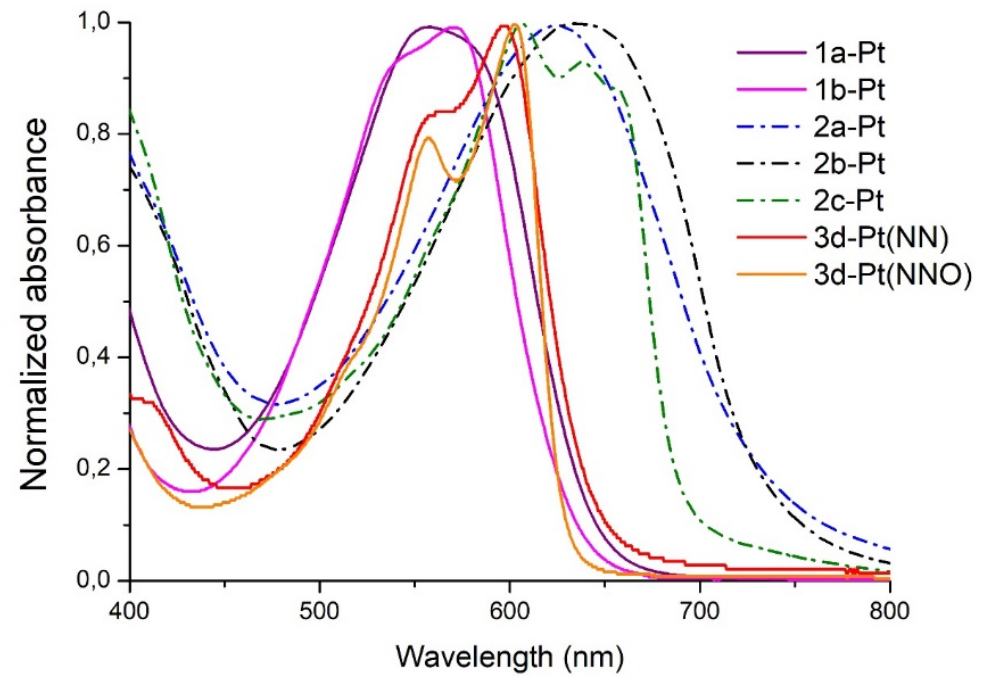

Figure 8. Absorption spectra of compounds 1-3-Pt at room temperature in $\mathrm{CH}_{2} \mathrm{Cl}_{2}$ solutions (except 2c-Pt in DMF solution). 
The chiroptical properties of the chiral compounds $\mathbf{1 b}$ and $\mathbf{1 b}$-Pt have been studied by circular dichroism (CD) measurements (Figures 9 and S6-S9). In solution, no CD signal can be observed for either the ligand or the complex. On the other hand, measurements on thin films show a small bathochromic shift of the absorption as well as the appearance of a CD signal for both $\mathbf{1} \mathbf{b}$ and $\mathbf{1 b} \mathbf{b} \mathbf{P t}$. Very interestingly, there is a sharp contrast between the CD spectra of the ligand and the complex, since in $\mathbf{1 b}$ a bisignate positive/negative Cotton effect is observed, while in the complex the bisignate band is reversed (Figures S7 and S9), indicating a change in the predominant helical twist of the DPPT chromophores upon complexation.

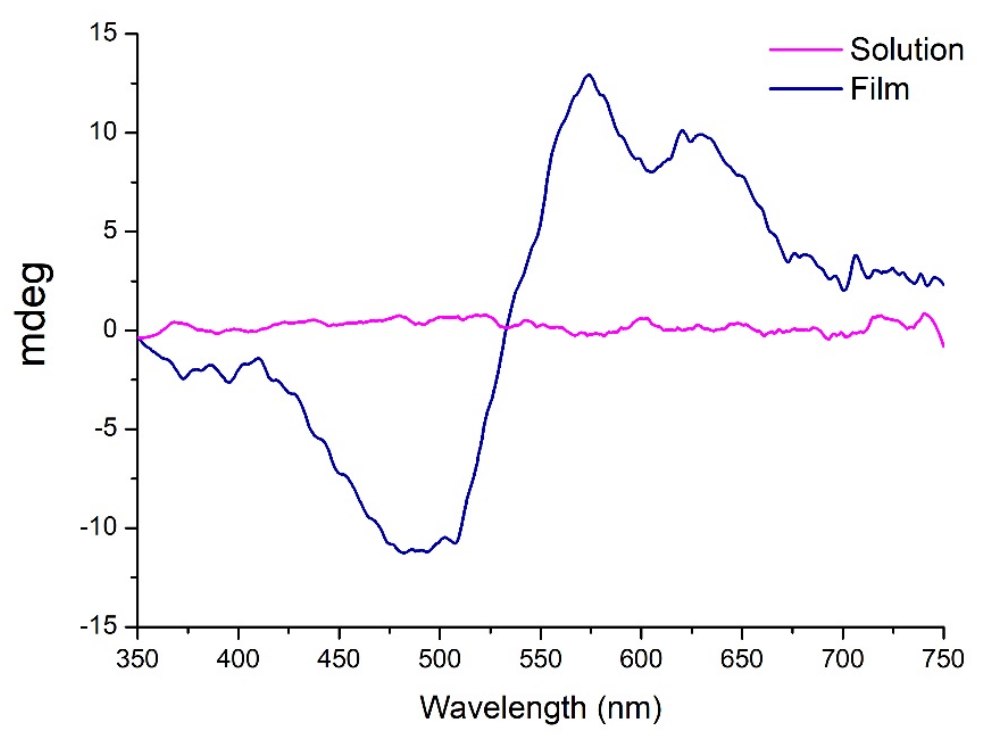

Figure 9. CD spectra of $1 \mathbf{b}$ in solution and in thin film at room temperature.

The cyclic voltammetry of the new ligands and related Pt complexes has been investigated in order to assign their oxidation and reduction potentials (Figures S10-S11). In agreement with the absorption spectra the extension of the conjugated system in $\mathbf{2}$ compared to 1 reduces the HOMO-LUMO gap rendering easier both the first reduction and first oxidation (Table S4). Whereas no change in the LUMO level was observed from $\mathbf{2}$ to its related complex $\mathbf{2}-\mathbf{P t}$, in $\mathbf{3}-\mathbf{P t}\left(\mathbf{N}^{\wedge} \mathbf{N}^{\wedge} \mathbf{O}\right)$ the LUMO level was raised by $0.26 \mathrm{~V}$ compared to ligand $\mathbf{3}$.

\subsection{Influence of the coordination modes of DPPT ligands on the photophysical properties}

When considering these compounds, three different coordination modes can be disclosed, each one inducing distinctive modulations of the optical properties. The tridentate coordination mode present in this work in the ortho-metalated compounds 1-,2-Pt and in the compound $\mathbf{3 d - P t}\left(\mathbf{N}^{\wedge} \mathbf{N}^{\wedge} \mathbf{O}\right)$ is noted as mode $\mathrm{A}$, and the bidentate coordination mode in compound $\mathbf{3 d}-\mathbf{P t}\left(\mathbf{N}^{\wedge} \mathbf{N}\right)$ as mode $B$ (Chart 2). In the two ortho-metalated DPPT-Pt(acac) complexes reported by Schanze et al., ${ }^{28}$ the Pt" metal ion is coordinated in a bidentate mode to the DPPT-based ligand, and the thiophene-pyridine coordination site is separated from the DPP core by an extra thiophene unit. Therefore the coordination mode

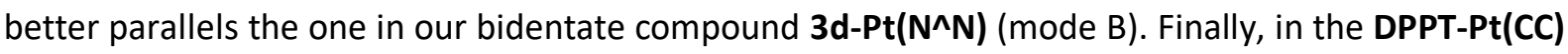
compound, the metal ion is coordinated through an acetylide bridge with no ortho-metalation, here noted as mode $\mathrm{C}$. 


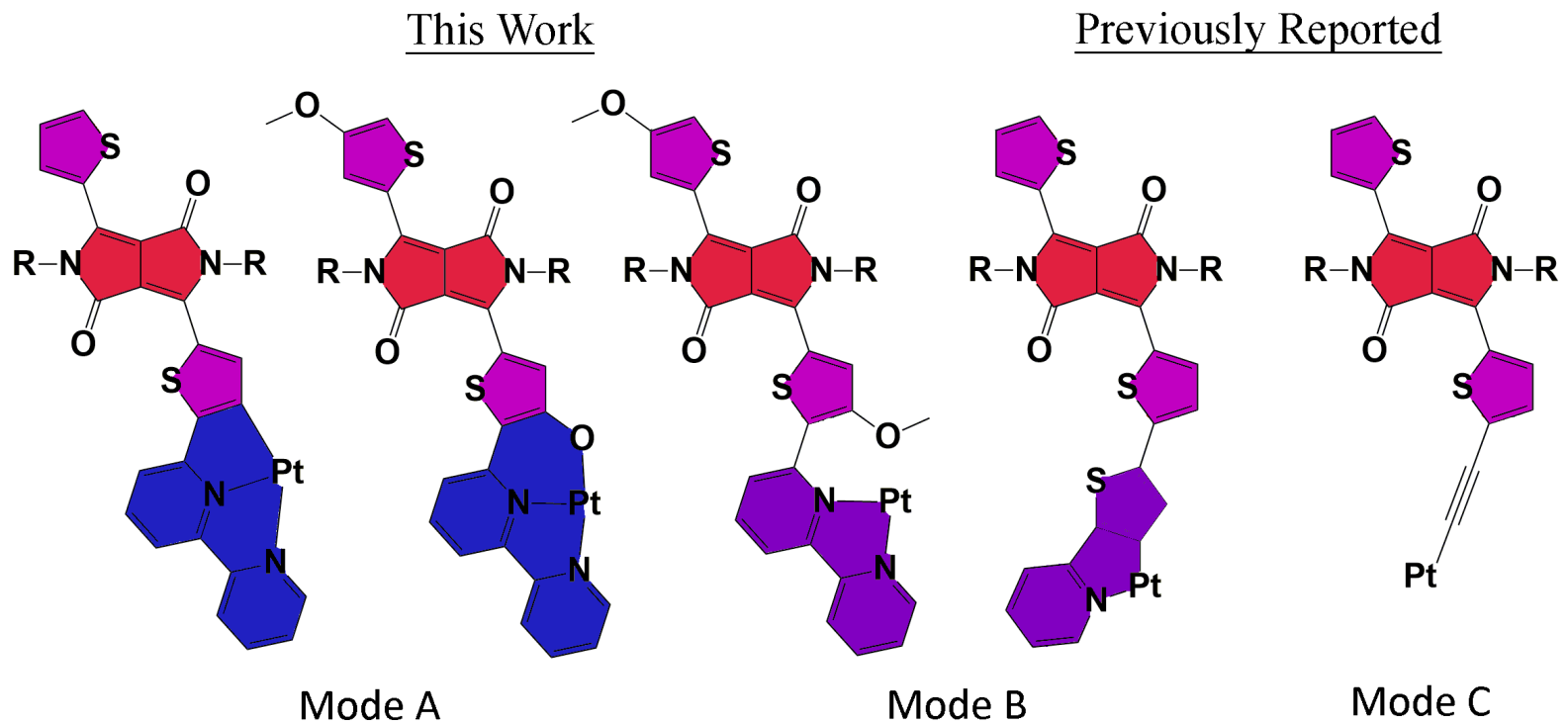

The coordination mode A strongly affects the optical properties of the DPPT chromophores. Compounds 1-Pt and 2-Pt show a strong decrease of the $\varepsilon_{\max }$ value compared to the related free ligands, and a significant bathochromic shift can be observed for the dinuclear complexes 2-Pt. This can be explained by an increased $\pi$-delocalization coupled with a more effective spin-orbit coupling due to the proximity of the heavy metal ion. Indeed, in the coordination mode A, the metal ion is linked in a tridentate mode to the DPPT chromophore and promoted the inclusion of two cyclometalated rings into the $\pi$-conjugated system. On the contrary, this is not observed in the coordination mode $B$. As a consequence, in $\mathbf{3 d}-\mathbf{P t}\left(\mathbf{N}^{\wedge} \mathbf{N}\right)$ the metalation barely affects the absorption of the molecule. The $\varepsilon_{\max }$ values are of the same order of magnitude for the ligand and the complex (around $4.10^{4}$ L.mol ${ }^{1} . \mathrm{cm}^{-1}$ ) and the maximum of absorption is almost unchanged. Note that in the study of Schanze et al. ${ }^{28}$ since the DPPT-Pt(acac) complexes were prepared by cross coupling reactions between the DPPT and the complex precursor $[\mathrm{Pt}(\mathrm{Br}$-thiophene-bpy)(acac)], the related free ligands were not isolated. However they observed a large bathochromic shift of about $110 \mathrm{~nm}$ between the DPPT and the DPPT$\mathrm{Pt}(\mathrm{acac})$ complexes which was attributed to the increase of the $\pi$-electron system, with only small contributions from Pt-based orbitals to the HOMO and LUMO. This is clearly confirmed in the spectra of $\mathbf{3 d}$ and $\mathbf{3 d - P t}$ since the coordination of the metal ion has a very little effect on the long-wavelength absorption values, which are here red-shifted by less than $10 \mathrm{~nm}$ in $\mathbf{3} \mathbf{d}-\mathbf{P t}(\mathbf{N} \wedge \mathbf{N})$ and $\mathbf{3 d}-\mathbf{P t}\left(\mathbf{N}^{\wedge} \mathbf{N}^{\wedge} \mathbf{O}\right)$. Moreover the spin-orbit coupling appears to be less effective in the mode $B$ complexes than in the mode A. This is further confirmed by a higher proportion of residual fluorescence of the DPPT chromophore after complexation. Indeed in $3 \mathbf{d}-\mathbf{P t}\left(\mathbf{N}^{\wedge} \mathbf{N}\right)$, the quantum yield of the fluorescence is $16 \%$, while it falls to $1 \%$ in compounds $\mathbf{1}-\mathbf{P t}, \mathbf{2}-\mathbf{P t}$ and below $1 \%$ in $\mathbf{3 d - P t}\left(\mathbf{N}^{\wedge} \mathbf{N}^{\wedge} \mathbf{O}\right)$. Finally, the coordination mode $C$ of the metal ion in DPPT-Pt(CC) resulted in a strong increase of the $\varepsilon_{\max }$ value $\left(11.10^{4} \mathrm{~L} . \mathrm{mol}^{-}\right.$ ${ }^{1} . \mathrm{cm}^{-1}$ ) compared to the DPPT-alkyne precursor and a reduction of the electronic bandgap confirmed by a bathochromic shift of about $50 \mathrm{~nm}$ at longer wavelength values. A moderate reduction of the fluorescence after complexation has been observed, with a small decrease of the quantum yield of fluorescence from $66 \%$ in the free ligand to $53 \%$ in the $\mathrm{Pt}$ " complex, probably due to a much lower spin-orbit coupling compared to the coordination modes $\mathrm{A}$ and $\mathrm{B}$. 


\subsection{Ab-initio calculations}

The observed differences in the absorption properties clearly reveal the importance of the orthometalation in this family of compounds. To clarify the origin of these differences, the electronic structure and optical properties of both ligands and complexes were investigated with the help of density functional theory (DFT) and time-dependent DFT calculations (see the Supporting Information for computational details). As observed experimentally, bathochromic shifts of about 10 and $60 \mathrm{~nm}$ were calculated for the SO->S1 excitation with the complexation of $\mathbf{1 b}$ and $\mathbf{2} \mathbf{b}$ into $\mathbf{1} \mathbf{b}-\mathbf{P t}$ and $\mathbf{2} \mathbf{b}-\mathbf{P t}$, respectively (Tables S5 and S6). For comparison, the complexation of the model ligand $\mathbf{3} \mathbf{b}$, containing an (S)-2-methyl-butyl chain instead of the dodecyl one, into $\mathbf{3 b}-\mathbf{P t}\left(\mathbf{N}^{\wedge} \mathbf{N}\right)$ and $\mathbf{3 b}-\mathbf{P t}\left(\mathbf{N}^{\wedge} \mathbf{N}^{\wedge} \mathbf{O}\right)$ induces shifts of only about $5 \mathrm{~nm}$ and $11 \mathrm{~nm}$, respectively. The nature of the transitions is represented with the help of the natural transition orbitals (NTOs) in Figure 10 for the complexes (see Figures S12 and S13 for ligands and complexes, respectively). In the three Pt complexes, the transitions correspond to a $\pi-\pi^{*}$ excitation with a very small contribution from the $5 \mathrm{~d}$ orbitals of the Pt centers, this latter going from ca. $4 \%$ in the HOMO of $\mathbf{1 b}-\mathbf{P t}$ and $\mathbf{2 b}-\mathbf{P t}$ to almost $0 \%$ in the HOMO of $\mathbf{3 b}-\mathbf{P t}\left(\mathbf{N}^{\wedge} \mathbf{N}\right)$.

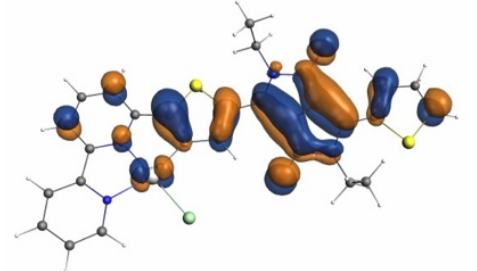

1b-Pt Occ.

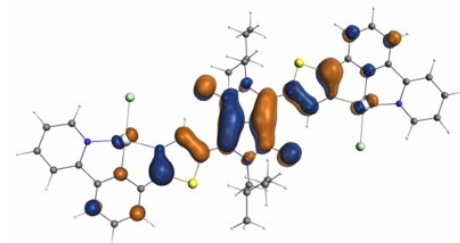

2b-Pt Occ.

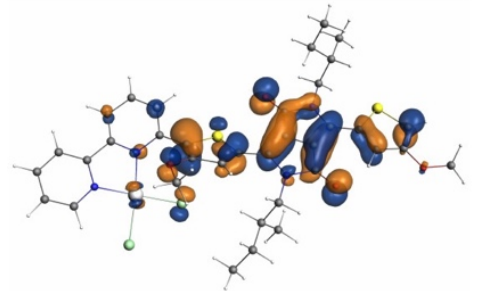

3b-Pt(NN) Occ.

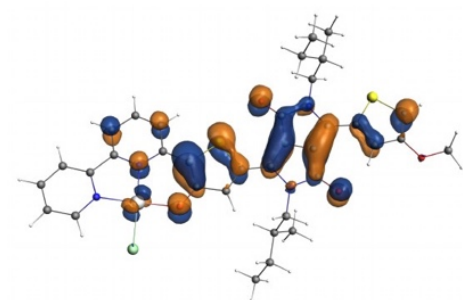

3b-Pt(NNO) Occ.

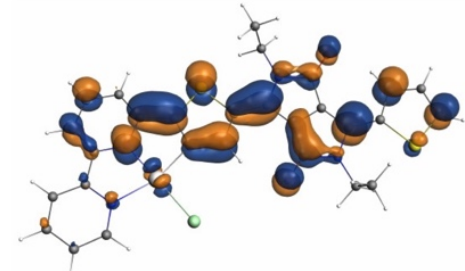

1b-Pt Virt.

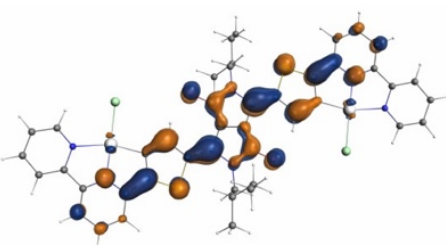

2b-Pt Virt.

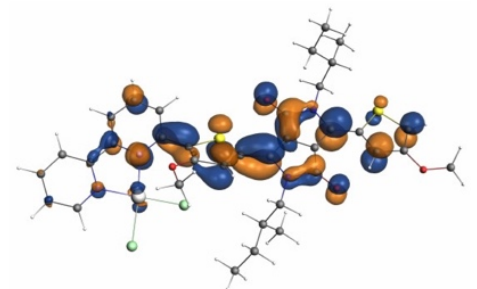

3b-Pt(NN) Virt.

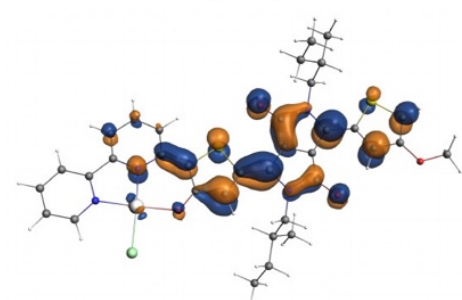

3b-Pt(NNO) Virt.

Figure 10. Natural transition orbitals (NTOs) calculated for the $\mathrm{SO}->\mathrm{S} 1$ transition in $\mathbf{1 b}-\mathbf{P t}, \mathbf{2 b}-\mathbf{P t}, \mathbf{3 b}-\mathbf{P t}\left(\mathbf{N}^{\wedge} \mathbf{N}\right)$ and 3b-Pt $\left(\mathbf{N}^{\wedge} \mathbf{N}^{\wedge} \mathbf{O}\right)$. Isosurface value $= \pm 0.03$ au.

The calculated UV-vis absorption spectra of $\mathbf{1 b} \mathbf{b} \mathbf{3} \mathbf{b}$ and their Pt" complexes accurately reproduce the experimental bathochromic shifts of the low-energy bands in $\mathbf{1 b} / \mathbf{1 b} \mathbf{b}-\mathbf{P t}$ and $\mathbf{2 b} / \mathbf{2} \mathbf{b}-\mathbf{P t}$, while in $\mathbf{3 b} \mathbf{b} \mathbf{3 b}$ - 
$\mathbf{P t}\left(\mathbf{N}^{\wedge} \mathbf{N}\right) / \mathbf{3 b}-\mathbf{P t}\left(\mathbf{N}^{\wedge} \mathbf{N}^{\wedge} \mathbf{O}\right)$ the band occurs at the same energy, as experimentally observed (Figures S14S16). Compared to the experimental spectra, the splitting of the first absorption and first emission bands is not reproduced theoretically. Such a behavior is attributed to the lack of considering vibronic effects in the calculations. Indeed, the introduction of vibronic effects in the calculated absorption and emission spectra of the ligand $\mathbf{1 b}$ (Figure 11) nicely reproduces the splitting of these bands. ${ }^{44}$

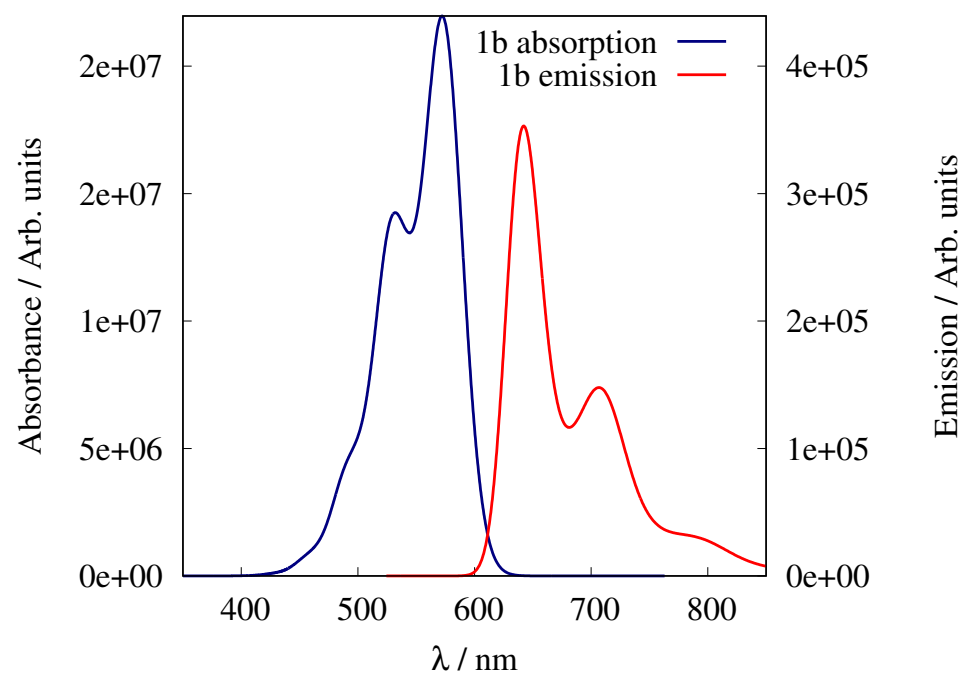

Figure 11. Calculated first absorption band (blue) and first emission band (red) of ligand $\mathbf{1 b}$ with introduction of vibronic effects.

\section{CONCLUSIONS}

Chelating monotopic and ditopic 2,2'-bipyridine (bpy) based diketopyrrolopyrrole-thiophene (DPPT) ligands 1-3 have been elegantly obtained following a direct cross-coupling strategy. The derivatization of the DPPT core with bpy has little influence on the emission properties, as shown by photophysical investigations, therefore the new ligands possess strong fluorescence in solution. The effect of the spin-orbit coupling on the emission properties has been investigated in a first series of ortho- and non ortho-metalated Pt" complexes. A very peculiar and unique reactivity has been observed with the methoxy containing ligand 3d. Unexpectedly, the complexation of the $\mathrm{PtCl}_{2}$ fragment by the bipyridine unit into $\mathbf{3 d}-\mathbf{P t}\left(\mathbf{N}^{\wedge} \mathbf{N}\right)$ is followed by cleavage of the $\mathrm{O}-\mathrm{Me}$ bond assisted by a second equivalent of platinum(II) precursor, affording the $3 \mathbf{d}-\mathbf{P t}\left(\mathbf{N}^{\wedge} \mathbf{N}^{\wedge} \mathrm{O}\right)$ complex where the ligand shows tridentate coordination mode. This reactional sequence has been further demonstrated by the use of the model ligand 3,4-dimethoxy-(2,2'-bipyridine) (DMTB) which afforded step wisely the complexes DMTB$\mathbf{P t}\left(\mathbf{N}^{\wedge} \mathbf{N}\right)$ and $\mathbf{P t}\left(\mathbf{N}^{\wedge} \mathbf{N}^{\wedge} \mathbf{O}\right)$, the latter being characterized by single-crystal X-ray diffraction. The orthometalation induces a high degree of planarity between the dpp core and the thiophene-bpy-Pt unit, expressed in the crystal structures of $\mathbf{1 a}-\mathbf{P t}$ and $\mathbf{1 b} \mathbf{b} \mathbf{P t}$ through the establishment of $\pi-\pi$ interactions. Moreover, short intermolecular Pt...Pt contacts are observed in the structure of $\mathbf{1 b} \mathbf{b} \mathbf{P t}$. The orthometalated complexes 1-2-Pt and the complex $3 \mathbf{d}-\mathbf{P t}\left(\mathbf{N}^{\wedge} \mathbf{N}^{\wedge} \mathrm{O}\right)$ present a strong spin-orbit coupling leading to a complete quenching of the fluorescence. On the other hand, the complex $\mathbf{3 d}-\mathbf{P t}\left(\mathbf{N}^{\wedge} \mathbf{N}\right)$ shows a residual fluorescence with a quantum yield of about $16 \%$, confirming the importance of the coordination mode of the metal (bidentate or tridentate) on the optical properties of the chromophore. TD DFT calculations emphasize the influence of the complexation in the absorption properties and demonstrate the vibronic nature of the dual splitting of the first absorption and emission bands of the DPPT derivatives. The easy preparation, modular coordination and emissive 
properties of the series of ligands 1-3 make them attractive for the coordination of other transition metals to provide multifunctional complexes. On the other hand, we are currently working on the preparation of photoconducting materials based on compound $\mathbf{3 d}-\mathbf{P t}\left(\mathbf{N}^{\wedge} \mathbf{N}\right)$ and electroactive ligands such as dithiolenes.

\section{EXPERIMENTAL SECTION}

4.1. Materials and methods. All reactions were carried out under Argon atmosphere using the Schlenk technique. The precursors $\left(C_{10}\right)_{2}$ DPPT, $\left(C_{5}\right)_{2}$ DPPT, $C_{5}$ HDPPT and $\left(C_{12}\right)_{2}$ DPPT were prepared as previously reported in the literature. ${ }^{45,46}$ Nuclear magnetic resonance spectra (Figures S17-S34) were recorded on a Bruker Avance DRX 300 spectrometer (operating at $300 \mathrm{MHz}$ for ${ }^{1} \mathrm{H}$ and $75 \mathrm{MHz}$ for ${ }^{13} \mathrm{C}$ ) or on a Bruker Avance DRX 500 (operating at $125 \mathrm{MHz}$ for ${ }^{13} \mathrm{C}$ ). Chemical shifts are expressed in parts per million (ppm) downfield from external TMS. The following abbreviations are used: $s$, singlet; $m$, multiplet; $\mathrm{H}_{\mathrm{TH}}, \mathrm{H}$ from thiophene; $\mathrm{H}_{\mathrm{PY}}, \mathrm{H}$ from pyridine. MALDI-TOF MS spectra (Figures S35-S55) were recorded on Bruker Biflex-IIITM apparatus, equipped with a $337 \mathrm{~nm} \mathrm{~N} \mathrm{~N}_{2}$ laser and exact mass determination on a Spiral-TOF Jeol JMS3000. Elemental analyses were recorded using Flash 2000 Fisher Scientific Thermo Electron analyser. UV-Vis absorption, excitation and emission spectra were recorded using Shimadzu UV 1800 and RF-6000 spectrometers in $10^{-5} \mathrm{M} \mathrm{CH}_{2} \mathrm{Cl}_{2}$ solutions (except for the monoalkylated DPP-based compounds $\mathbf{2 c}$ and $\mathbf{2 c}$-Pt which have been measured respectively in THF and DMF solutions for solubility reasons). The quantum yields of fluorescence have been determined using cresyl violet perchlorate as standard reference. CD spectra were recorded on a JASCO J-1500 spectrometer at $20^{\circ} \mathrm{C}$. Cyclic voltammetry was measured in $\mathrm{CH}_{2} \mathrm{Cl}_{2}$ using platinum working and counter electrodes and an $\mathrm{Ag} / \mathrm{Ag}^{+}$pseudo-reference electrode in $0.1 \mathrm{MnBu}_{4} \mathrm{PF}_{6}$ as supporting electrolyte, with a scan rate of 100 $\mathrm{mV} . \mathrm{s}^{-1}$. All potentials are reported relative to an $\mathrm{Fc} / \mathrm{Fc}^{+}$internal standard.

4.2. Synthesis of the organic DPPT derivatives (1-3). The DPPT precursors $\left(\left(C_{10}\right)_{2}\right.$ DPPT, $\left(C_{5}\right)_{2}$ DPPT, $\mathrm{C}_{5}$ HDPPT or $\left.\left(\mathrm{C}_{12}\right)_{2} \mathrm{DPPT}\right)$ (1 mmol), 6-bromo-2,2'-bipyridine (1 mmol for 1a,b, 2ab and 3d, $2 \mathrm{mmol}$ for 2c), $\mathrm{K}_{2} \mathrm{CO}_{3}(2 \mathrm{mmol}), \mathrm{Pd}(\mathrm{OAc})_{2}(0.18 \mathrm{mmol})$ and pivalic acid $(0.12 \mathrm{mmol})$ were dissolved in anhydrous dimethylacetamide $(8 \mathrm{~mL})$ under inert atmosphere. The mixture was placed in the microwave for 40 $\min \left(\mathrm{T}=180^{\circ} \mathrm{C}, \mathrm{P}=10 \mathrm{bar}\right)$. The product was extracted with dichloromethane or tetrahydrofuran and washed with brine. The organic phase was dried with $\mathrm{Mg}_{2} \mathrm{SO}_{4}$ anhydrous and concentrated under vacuum. The crude product was purified by column chromatography on silica gel using $\mathrm{CH}_{2} \mathrm{Cl}_{2}$ followed by $\mathrm{CH}_{2} \mathrm{Cl}_{2}: \mathrm{AcOEt} 1 / 1$ as eluents.

$\left(C_{10}\right)_{2}$ DPPT: Two fractions were obtained corresponding to $1 \mathrm{a}$ and $\mathbf{2 a}$ (yields: $1 \mathrm{a}, 39 \% ; \mathbf{2 a}, 5 \%$ ).

$\left(C_{5}\right)_{2} D P P T$ : Two fractions were obtained corresponding to $\mathbf{1 b}$ and $\mathbf{2 b}$ (yields: $\mathbf{1 b}, \mathbf{3 0} ; \mathbf{2} \mathbf{b}, \mathbf{5 \%}$ ).

$C_{5}$ HDPPT: One fraction was obtained corresponding to $2 c$ (yield $18 \%$ ).

$\left(C_{12}\right)_{2}$ DPPT: One fraction was obtained corresponding to $\mathbf{3 d}$ (yield $17 \%$ ).

1a: ${ }^{1} \mathrm{H}-\mathrm{NMR}\left(300 \mathrm{MHz}, \mathrm{CDCl}_{3}\right.$ ). $\delta: 9.07$ (d, H9, J = 4.2 Hz), 8.95 (dd, H10, J = 3.9, $\left.0.9 \mathrm{~Hz}\right), 8.68$ (d, H4, J = $4.1 \mathrm{~Hz}$ ), 8.53 (d, H5, J = 7.9 Hz), 8.35 (d, H1, J = 7.7 Hz), 7.84 (td, H2-H6, J = 8.0 Hz), 7.75-7.68 (m, H7H8), 7.62 (d, H12, J = 5.0 Hz), 7.34 (ddd, H3, J = 7.5, 4.8, 0.9 Hz), 7.27 (t, H11, J = 4.5 Hz), 4.17 (t, H13$\mathrm{H} 14, \mathrm{~J}=7.5 \mathrm{~Hz}), 4.05(\mathrm{t}, \mathrm{H} 15-\mathrm{H} 16, \mathrm{~J}=7.5 \mathrm{~Hz}), 1.79(\mathrm{~m}, 4 \mathrm{H}), 1.61-1.40(\mathrm{~m}, 4 \mathrm{H}), 1.45-1.11(\mathrm{~m}, 24 \mathrm{H})$, 0.94-0.83 (m, 6H). ${ }^{13} \mathrm{C}-\mathrm{NMR}\left(75 \mathrm{MHz}, \mathrm{CDCl}_{3}\right) .8: 161.7,161.6,156.2,155.7,151.0,150.7,149.5,140.4$, 140.2 , 138.1, 137.3, 137.2, 135.7, 131.4, 131.0, 130.2, 128.9, 125.8, 124.4, 121.5, 120.5, 119.5, 108.5, 108.3, 42.7, 42.6, 32.2, 32.2, 30.4, 30.3, 30.0, 29.9, 29.7, 29.6, 29.6, 27.4, 27.2, 23.0, 23.0, 14.5, 14.4. MALDI (positive mode): $735.4\left(1 \mathrm{a}+\mathrm{H}^{+}\right)$. Anal. Calcd for $\mathrm{C}_{44} \mathrm{H}_{54} \mathrm{~N}_{4} \mathrm{O}_{2} \mathrm{~S}_{2}: \mathrm{C} 71.90, \mathrm{H} 7.40, \mathrm{~N}$ 7.62, S 8.72. Found: C 71.60, H 7.49, N 7.28, S 8.36. 
1b: ${ }^{1} \mathrm{H}-\mathrm{NMR}\left(300 \mathrm{MHz}, \mathrm{CDCl}_{3}\right) .8: 9.15(\mathrm{~d}, \mathrm{H9}, J=4.5 \mathrm{~Hz}$ ), 9.00 (d, H10, J=3.9 Hz), 8.70 (d, H4, J = 4.5 $\mathrm{Hz}), 8.56(\mathrm{~d}, \mathrm{H} 5, J=8.2 \mathrm{~Hz}), 8.39(\mathrm{~d}, \mathrm{H} 1, J=7.8 \mathrm{~Hz}), 7.93-7.82(\mathrm{td}, \mathrm{H} 2-\mathrm{H6}, \mathrm{J}=7.5 \mathrm{~Hz}), 7.77(\mathrm{~d}, \mathrm{H} 7, \mathrm{~J}=$ $8.1 \mathrm{~Hz}$ ), 7.75 (d, H8, J = 4.2 Hz), 7.64 (d, H12, J = 5.1 Hz), 7.35 (ddd, H3, J = 7.8, 4.8, 0.9 Hz), 7.27 (t, H11, $J=4.2 \mathrm{~Hz}), 4.12(\mathrm{t}, \mathrm{H} 13-\mathrm{H} 14, J=7.8 \mathrm{~Hz}), 4.02(\mathrm{dd}, \mathrm{H} 15-\mathrm{H} 16, J=7.3,6.9 \mathrm{~Hz}), 2.11(\mathrm{~m}, 1 \mathrm{H}), 1.94(\mathrm{~m}, 1 \mathrm{H})$, 1.62-1.48 $(\mathrm{m}, 2 \mathrm{H}), 1.38-1.20(\mathrm{~m}, 2 \mathrm{H}), 1.01(\mathrm{q}, 6 \mathrm{H}, \mathrm{J}=3.6 \mathrm{~Hz}), 0.92(\mathrm{~m}, 6 \mathrm{H})$. The extra peak at $1.56 \mathrm{ppm}$ comes from $\mathrm{H}_{2} \mathrm{O}$ solvent molecules. ${ }^{13} \mathrm{C}-\mathrm{NMR}\left(125 \mathrm{MHz}, \mathrm{CDCl}_{3}\right) . \delta 161.8,161.7,155.9,155.5,150.7$, $150.5,149.2,140.5,140.2$, 137.9, 137.3, 136.9, 135.7, 131.1, 130.7, 130.0, 128.6, 125.3, 124.1, 121.2, $120.2,119.1,108.2,108.1,77.5,77.1,76.6,47.7,47.7,35.8,35.5,27.2,27.0,16.8,16.6,11.4,11.3$. MALDI (positive mode): 594.1 (1b). Anal. Calcd for $\mathrm{C}_{34} \mathrm{H}_{34} \mathrm{~N}_{4} \mathrm{O}_{2} \mathrm{~S}_{2}$ : C 68.66, H 5.76, N 9.42, S 10.78 . Found: C 68.11, H 5.73, N 9.18, S 10.63.

2a: ${ }^{1} \mathrm{H}$ NMR $\left(300 \mathrm{MHz}, \mathrm{CDCl}_{3}\right) \delta 9.13(\mathrm{~d}, 2 \mathrm{H9}, J=4.2 \mathrm{~Hz}), 8.70(\mathrm{~d}, 2 \mathrm{H} 4, J=4.5 \mathrm{~Hz}), 8.56(\mathrm{~d}, 2 \mathrm{H} 5, J=8.1$ $\mathrm{Hz}$ ), 8.38 (d, $2 \mathrm{H6}, J=7.9 \mathrm{~Hz}$ ), 7.87 (m, $2 \mathrm{H} 2$ - $2 \mathrm{H6}$ ), 7.79-7.74 (m, $2 \mathrm{H7}-2 \mathrm{H8}), 7.36$ (dd, $2 \mathrm{H3}, J=6.4$, $4.9 \mathrm{~Hz}), 4.26-4.20$ (m, H10-H11-H12-H13), 1.90-1.74 (br, 4H), 1.47-1.39 (br, 4H), 1.32-1.20 (br, 24H), $0.85(\mathrm{~m}, 6 \mathrm{H})$. The extra peak at $1.56 \mathrm{ppm}$ comes from $\mathrm{H}_{2} \mathrm{O}$ solvent molecules. ${ }^{13} \mathrm{C}$-NMR of the sample was not successful because of its low solubility in the chosen solvent (please see attached figure in the SI). MALDI (positive mode): $889.5\left(2 \mathrm{a}+\mathrm{H}^{+}\right)$.

2b: ${ }^{1} \mathrm{H}-\mathrm{NMR}\left(300 \mathrm{MHz}, \mathrm{CDCl}_{3}\right.$ ). $8: 9.19$ (d, $2 \mathrm{Hg}, \mathrm{J}=4.2 \mathrm{~Hz}$ ), 8.70 (d, $2 \mathrm{H} 4, J=4.6 \mathrm{~Hz}$ ), 8.56 (d, $2 \mathrm{H} 5, J=$ $7.9 \mathrm{~Hz}), 8.38(\mathrm{~d}, 2 \mathrm{H1}, J=7.7 \mathrm{~Hz}), 7.88(\mathrm{q}, 2 \mathrm{H} 2-2 \mathrm{H6}, J=7.4 \mathrm{~Hz}), 7.79-7.73(\mathrm{~m}, 2 \mathrm{H7}-2 \mathrm{H8}), 7.38-7.32$ $(\mathrm{m}, 2 \mathrm{H} 3), 4.18-4.08(\mathrm{~m}, 2 \mathrm{H} 10$ - $2 \mathrm{H} 11), 2.16-2.07(\mathrm{~m}, 2 \mathrm{H}), 1.69-1.56(\mathrm{~m}, 2 \mathrm{H}), 1.41-1.29(\mathrm{~m}, 2 \mathrm{H}), 1.03$ $(\mathrm{t}, 6 \mathrm{H}, J=6.1 \mathrm{~Hz}), 0.88-0.78(\mathrm{~m}, 6 \mathrm{H})$. The extra peak at 1.56 comes from $\mathrm{H}_{2} \mathrm{O}$ solvent molecules. ${ }^{13} \mathrm{C}-$ NMR of the sample was not successful because of its low solubility in the chosen solvent. MALDI (positive mode): 748.2 (2b).

2c: ${ }^{1} \mathrm{H}-\mathrm{NMR}$ (300 MHz, THF-d8). $\delta: 10.83$ (NH), 9.21 (d, H9, J = 4.2 Hz), 8.71 (d, H10, J = 4.2 Hz), 8.65 (dd, $2 \mathrm{Hth}, J=4.5,0.9 \mathrm{~Hz}), 8.59$ (d, $2 \mathrm{Hpy}, J=8.1 \mathrm{~Hz}), 8.43$ (dt, $2 \mathrm{Hpy}, J=6.4,2.1 \mathrm{~Hz}), 7.96-7.85(\mathrm{~m}, 6$ Hpy - H8 - H11), $7.40-7.33$ (dd, $2 \mathrm{Hpy}, \mathrm{J}=7.5,4.8 \mathrm{~Hz}$ ), $4.17-4.12$ (m, H19-H20), 1.35-1.28 (m, 2H), $1.03(\mathrm{~m}, 6 \mathrm{H})$. The extra peak at $3.57 \mathrm{ppm}$ comes from $\mathrm{H}_{2} \mathrm{O}$ solvent molecules. ${ }^{13} \mathrm{C}-\mathrm{NMR}(125 \mathrm{MHz}$, $\mathrm{CDCl}_{3}$ ). $\delta: 161.6,161.0,155.9,155.9,155.4,155.3,150.9,150.9,150.2,150.0,149.1,149.1,138.7$, $137.8,137.7,137.2,136.7,136.5,136.5,134.0,132.4,131.6,126.2,125.3,123.9,120.5,120.5,119.8$, 119.0, 119.0, 53.9, 47.1, 35.9, 29.7, 27.0, 16.1, 13.5, 10.7. MALDI (positive mode): $679.1\left(2 \mathrm{c}+\mathrm{H}^{+}\right)$.

3d: ${ }^{1} \mathrm{H}-\mathrm{NMR}\left(300 \mathrm{MHz}, \mathrm{CDCl}_{3}\right) .8: 9.17(\mathrm{~s}, \mathrm{H} 8), 8.69$ (d, H1, J = 4.0 Hz), $8.62(\mathrm{~d}, \mathrm{H} 9,1.7 \mathrm{~Hz}), 8.50$ (d, H5, $8.0 \mathrm{~Hz}$ ), 8.29 (d, H4, J = 7.8 Hz), 8.17 (d, H6, J = 7.8 Hz), 7.83 (m, H2-H7), 7.32 (ddd, H3, J = 7.2, 4.8, 0.9 $\mathrm{Hz}), 6.62(\mathrm{~d}, \mathrm{H} 10,1.5 \mathrm{~Hz}), 4.20(\mathrm{~s}, \mathrm{H} 18-\mathrm{H} 19-\mathrm{H} 20), 4.20(\mathrm{t}, \mathrm{H} 16-\mathrm{H} 17, \mathrm{~J}=7.8 \mathrm{~Hz}), 4.05(\mathrm{t}, \mathrm{H} 14-\mathrm{H} 15, \mathrm{~J}=7.5$ $\mathrm{Hz}), 3.91(\mathrm{~s}, \mathrm{H} 11-\mathrm{H} 12-\mathrm{H} 13), 1.80(\mathrm{~m}, 4 \mathrm{H}), 1.29(\mathrm{~m}, 36 \mathrm{H}), 0.86(\mathrm{~m}, 6 \mathrm{H}) .{ }^{13} \mathrm{C}-\mathrm{NMR}\left(75 \mathrm{MHz}, \mathrm{CDCl}_{3}\right) . \delta$ : $161.5,159.4,156.8,139.5,138.1,128.3,125.2,108.4,104.5,58.0,52.4,47.1,42.6,32.1,30.2,30.1$, 29.9, 29.8, 29.7, 29.5, 27.3, 27.0, 22.8, 14.3. MALDI (positive mode): 850.5 (3d).

4.3. Synthesis of DMTB. 3,4-Dimethoxythiophene ( $1 \mathrm{mmol})$, 6-bromo-2,2'-bipyridine ( $1 \mathrm{mmol}), \mathrm{K}_{2} \mathrm{CO}_{3}$ $(2 \mathrm{mmol}), \mathrm{Pd}(\mathrm{OAc})_{2}(0.18 \mathrm{mmol})$ and pivalic acid $(0.12 \mathrm{mmol})$ were dissolved in anhydrous dimethylacetamide $(4 \mathrm{~mL})$ under inert atmosphere. The mixture was placed in the microwave for 40 $\min \left(\mathrm{T}=180^{\circ} \mathrm{C}, \mathrm{P}=10 \mathrm{bar}\right)$. The product was precipitated with water, filtered and the solid was extracted with dichloromethane. The organic phase was dried with $\mathrm{Mg}_{2} \mathrm{SO}_{4}$ anhydrous and concentrated under vacuum. The crude product was purified by column chromatography on silica gel using $\mathrm{CH}_{2} \mathrm{Cl}_{2}$ as eluent affording pure DMTB in $40 \%$ yield. ${ }^{1} \mathrm{H}-\mathrm{NMR}\left(300 \mathrm{MHz}, \mathrm{CDCl}_{3}\right) .8: 8.67(\mathrm{~d}, \mathrm{H} 4, \mathrm{~J}=$ $4.1 \mathrm{~Hz}$ ), 8.54 (d, H5, J = 8.0 Hz), 8.26 (dd, H1, J = 7.8, $0.9 \mathrm{~Hz}$ ), 8.07 (dd, H6, J = 7.9, 0.9 Hz), 7.87-7.80 (m, $\mathrm{H} 2-\mathrm{H} 7$ ), 7.31 (ddd, H3, J = 7.5, 4.8, $1.2 \mathrm{~Hz}$ ), 6.31 (s, H8), 3.97 (s, H14-H15-H16), 3.89 (s, H11-H12-H13). 
${ }^{13} \mathrm{C}-\mathrm{NMR}\left(75 \mathrm{MHz}, \mathrm{CDCl}_{3}\right) . \quad \delta: 156.07,155.2,151.4,150.8,149.1,137.8,137.0,123.9,121.4,120.5$, 119.0, 97.9, 60.3, 57.4.

4.4. Synthesis of the DPPT-based complexes 1-2-Pt. $\mathrm{PtCl}_{2}(\mathrm{DMSO})_{2}(0.03 \mathrm{mmol}, 13 \mathrm{mg})$ was added to a $10 \mathrm{~mL}$ dichloromethane solution of the corresponding DPPT ligand $(0.03 \mathrm{mmol})$ and the mixture was stirred under reflux overnight. The resulting solution was concentrated under vacuum and the crude product was washed with methanol to remove the unreacted free ligand. The residue was dissolved in dichloromethane and concentrated under vacuum. The absence of free ligand in the filtrate was confirmed by TLC $\left(\mathrm{CH}_{2} \mathrm{Cl}_{2} / \mathrm{AcOEt}\right.$ : $\left.95 / 5 \%\right)$. After recrystallization from a mixture of $\mathrm{CHCl}_{3} / \mathrm{DMF}$, single crystals of compounds $\mathbf{1 a}$-Pt and $\mathbf{1 b}$-Pt could be obtained and used for structure determination by $\mathrm{X}$ ray diffraction. Yields: 83\% (1a-Pt), 88\% (1b-Pt), 28\% (2a-Pt), 24\% (2b-Pt), 34\% (2c-Pt). MALDI (positive mode): 962 (compound 1a-Pt); 823 (1b-Pt); 1345 (2a-Pt); 1205 (2b-Pt); 1134 (2c-Pt). Exact mass: compound 1a-Pt: 962.2927 (theoretical for $\mathrm{C}_{34} \mathrm{H}_{33} \mathrm{~N}_{4} \mathrm{O}_{2} \mathrm{~S}_{2} \mathrm{ClPt}$ : 962.2925 ).

1b-Pt: ${ }^{1} \mathrm{H}-\mathrm{NMR}\left(300 \mathrm{MHz}, \mathrm{CDCl}_{3}\right.$ ). $8: 9.03$ (m, H8), 8.88 (m, H7), 7.95 (m, Hpy - $2 \mathrm{Hth}$ ), 7.67 (m, 2 Hpy), 7.58 (m, H7), 7.46 (m, H3), 7.28 (m, H10), 7.21 (m, H2) 3.99 (m, H12-H13-H14-H15), 2.17 (s, 2H), 1.92 $(\mathrm{m}, 4 \mathrm{H}), 0.92(\mathrm{~m}, 12 \mathrm{H})$. The extra peaks at $1.56 \mathrm{ppm}$ and $1.23 \mathrm{ppm}$ come from $\mathrm{H}_{2} \mathrm{O}$ and AcOEt solvent molecules.

4.5. Synthesis of $3 \mathrm{~d}-\mathrm{Pt}\left(\mathrm{N}^{\wedge} \mathrm{N}\right) \cdot \mathrm{PtCl}_{2}(\mathrm{DMSO})_{2}(0.03 \mathrm{mmol}, 13 \mathrm{mg})$ was added to a $10 \mathrm{~mL}$ dichloromethane solution of the corresponding DPPT ligand $(0.03 \mathrm{mmol})$ and the mixture was stirred at room temperature overnight. The resulting solution was concentrated under vacuum and the crude product was washed with diethylether and methanol to remove the unreacted free ligand. The residue was dissolved in dichloromethane and concentrated under vacuum. A small amount of pure sample has been obtained after several washings with various solvents and the yield could not be determined in these conditions. The absence of free ligand in the filtrate was confirmed by $\operatorname{TLC}\left(\mathrm{CH}_{2} \mathrm{Cl}_{2} / \mathrm{AcOEt}\right.$ : 95/5\%). MALDI (positive mode): $1079\left(\mathbf{3 d - P t}\left(\mathbf{N}^{\wedge} \mathbf{N}\right)-\mathrm{Cl}^{-}\right)$. Exact mass: 1079.3854 (theoretical for $\mathrm{C}_{50} \mathrm{H}_{66} \mathrm{~N}_{4} \mathrm{O}_{4} \mathrm{~S}_{2} \mathrm{ClPt}:$ 1079.3835).

4.6. Synthesis of $3 \mathrm{~d}-\mathrm{Pt}\left(\mathrm{N}^{\wedge} \mathrm{N}^{\wedge} \mathrm{O}\right) . \mathrm{PtCl}_{2}\left(\mathrm{DMSO}_{2}(0.06 \mathrm{mmol}, 26 \mathrm{mg})\right.$ was added to a $10 \mathrm{~mL}$ dichloromethane solution of the corresponding DPPT ligand $(0.03 \mathrm{mmol})$ and the mixture was stirred under reflux for $24 \mathrm{~h}$. After removal of the solvent under vacuum, the crude product was purified by column chromatography on silica gel using $\mathrm{CH}_{2} \mathrm{Cl}_{2}$ followed by $\mathrm{CH}_{2} \mathrm{Cl}_{2}$ :AcOEt $1 / 1$ as eluents. Yield: $66 \%$. MALDI (positive mode): 1064 (3d-Pt( $\left(\mathbf{N}^{\wedge} \mathbf{N}^{\wedge} \mathbf{O}\right)$ ). Exact mass: 1064.3598 (theoretical for $\mathrm{C}_{49} \mathrm{H}_{63} \mathrm{~N}_{4} \mathrm{O}_{4} \mathrm{~S}_{2} \mathrm{ClPt}:$ 1064.3598). ${ }^{1} \mathrm{H}-\mathrm{NMR}\left(300 \mathrm{MHz}, \mathrm{CDCl}_{3}\right)$. $\delta: 9.62$ (d, H4, J = 4.8 Hz), $8.68(\mathrm{~m}, \mathrm{H} 5), 8.00$ (m, H1-H9-H10), 7.72 (m, H6-H7-H8, 7.8 Hz), 7.40 (m, H3), 6.66 (m, H2), 4.07-3.97 (m, H14-H15-H16$\mathrm{H} 17), 3.90(\mathrm{~s}, \mathrm{H} 11-\mathrm{H} 12-\mathrm{H} 13), 1.77-1.67(\mathrm{~m}, 4 \mathrm{H}), 1.25-1.21(\mathrm{~m}, 36 \mathrm{H}), 0.85(\mathrm{~m}, 6 \mathrm{H})$.

4.7. Synthesis of DMTB-Pt( $\left.\mathbf{N}^{\wedge} \mathbf{N}\right)$. To a dichloromethane solution of dimethoxy-thiophenyl-bipyridine (DMTB, $0.03 \mathrm{mmol}$ ) was added two equivalents of $\mathrm{PtCl}_{2}(\mathrm{DMSO})_{2}(0.03 \mathrm{mmol}, 13 \mathrm{mg})$ and the mixture was stirred at room temperature overnight. After concentration of the solvent under vacuum and washing of the crude product by precipitation with diethylether, the compound $\mathbf{D M T B}-\mathbf{P t}\left(\mathbf{N}^{\wedge} \mathbf{N}\right)$ was isolated as an orange powder after slow evaporation of a chloroform solution Yield: $35 \%$. ${ }^{1} \mathrm{H}-\mathrm{NMR}$ (300 $\left.\mathrm{MHz}, \mathrm{CDCl}_{3}\right) .8: 8.70(\mathrm{~m}, \mathrm{H1}), 8.54(\mathrm{~d}, \mathrm{H} 5, \mathrm{~J}=8.1 \mathrm{~Hz}), 8.28(\mathrm{~d}, \mathrm{H} 4, \mathrm{~J}=7.6 \mathrm{~Hz}), 8.08(\mathrm{~m}, \mathrm{H6}), 7.90-7.82(\mathrm{~m}$, H2-H7), 7.34 (m, H3), 6.32 (s, H8), 3.97 (s, H14-H15-H16), 3.89 (s, H11-H12-H13). MALDI (positive mode): 527.1. Exact mass: 527.0085 (theoretical for $\mathrm{C}_{16} \mathrm{H}_{14} \mathrm{~N}_{2} \mathrm{O}_{2} \mathrm{SClPt}$ : 527.0085).

4.8. Synthesis of DMTB-Pt( $\left.\mathbf{N}^{\wedge} \mathbf{N}^{\wedge} \mathrm{O}\right)$. To a dichloromethane solution of dimethoxy-thiophenylbipyridine (DMTB, $0.03 \mathrm{mmol})$ was added two equivalents of $\mathrm{PtCl}_{2}(\mathrm{DMSO})_{2}(0.03 \mathrm{mmol}, 13 \mathrm{mg})$ and the mixture was stirred under reflux overnight. After removal of the solvent under vacuum, the crude product was purified by column chromatography on silica gel using $\mathrm{CH}_{2} \mathrm{Cl}_{2}$ followed by $\mathrm{CH}_{2} \mathrm{Cl}_{2}$ : $\mathrm{AcOEt}$ 
$1 / 1$ as eluents. After recrystallization from a chloroform/dichloromethane solution, single crystals of compound DMTB-Pt( $\left(\mathbf{N}^{\wedge} \mathbf{N}^{\wedge} \mathrm{O}\right)$ could be obtained and used for structure determination by X-ray diffraction. Yield: 68\%. ${ }^{1} \mathrm{H}-\mathrm{NMR}\left(300 \mathrm{MHz}, \mathrm{CDCl}_{3}\right) .8: 9.56(\mathrm{~d}, \mathrm{H1}, \mathrm{J}=5.0 \mathrm{~Hz}), 8.01(\mathrm{~m}, \mathrm{H} 2-\mathrm{H} 6-\mathrm{H} 7), 7.70$ (d, H4, J= 7.0 Hz), 7.52 (d, H5, J = 8.3 Hz), 7.35 (td, H3, J = 6.1, $2.6 \mathrm{~Hz}$ ), 6.33 (s, H8), 3.88 (s, H11-H12H13). MALDI (positive mode): 513.1. Exact mass: 512.9929 (theoretical for $\mathrm{C}_{15} \mathrm{H}_{11} \mathrm{~N}_{2} \mathrm{O}_{2} \mathrm{SClPt}$ : 512.9929).

4.9. X-ray Crystallography. Single crystals of compounds $\mathbf{1 b}$, 1a-Pt, $\mathbf{1 b}-\mathbf{P t}$ and $\mathrm{DMTB}-\mathrm{Pt}\left(\mathrm{N}^{\wedge} \mathrm{N}^{\wedge} \mathrm{O}\right)$ were mounted on glass fiber loops using a viscous hydrocarbon oil to coat the crystal and then transferred directly to the cold nitrogen stream. Data collection were performed at $150 \mathrm{~K}$ on an Agilent Supernova with $\mathrm{Cu}-K_{\alpha}(\lambda=1.54184 \AA)$. The structures were solved by direct methods with the SIR97 program and refined all $F^{2}$ values with the SHELXL-2016/4 program using the WinGX graphical user interface. All non-hydrogen atoms were refined anisotropically. All hydrogen atoms were placed in calculated positions and refined isotropically with a riding model. A summary of the crystallographic data and the structure refinement is given in Table S1. CCDC 2043947 (1b), 2043948 (1a-Pt), 2043949 (1b-Pt) and 2059865 (DMTB-Pt(N^N^) )) contain the supplementary crystallographic data for the paper. These data can be obtained free of charge from The Cambridge Crystallographic Data Centre.

\section{ASSOCIATED CONTENT}

\section{Supporting Information}

The Supporting Information is available free of charge on the ACS Publications website at DOI:... Additional figures as mentioned in the text.

\section{Accession Codes}

CCDC 2043947 (1b), 2043948 (1a-Pt), 2043949 (1b-Pt) and 2059865 (DMTB-Pt(N^N^0)) contain the supplementary crystallographic data for this paper. These data can be obtained free of charge via www.ccdc.cam.ac.uk/data_request/cif, or by emailing data_request@ccdc.cam.ac.uk, or by contacting The Cambridge Crystallographic Data Centre, 12 Union Road, Cambridge CB2 1EZ, UK; fax: +44 1223336033 .

\section{AUTHOR INFORMATION}

\section{Corresponding Authors}

*N.A.: e-mail: narcis.avarvari@univ-angers.fr; fax: (+33)02 417354 05; tel, (+33)02 41735084.

*F.P: e-mail: flavia.pop@univ-angers.fr

\section{ORCID}

Alexandre Abhervé: 0000-0002-3883-310X

Boris Le Guennic: 0000-0003-3013-0546

Frédéric Gendron : 0000-0002-1896-3978

Flavia Pop: 0000-0003-3524-9781 
Narcis Avarvari: 0000-0001-9970-4494

\section{Notes}

The authors declare no competing financial interest.

\section{ACKNOWLEDGMENTS}

This work was supported in France by the CNRS, the University of Angers, the RFI LUMOMAT (CHIMAERA Project) and the UBL (grant to A.A.). The Erasmus exchange program between the University of Angers, France, and University of Cagliari, Italy, is acknowledged (internship grant to S.B.). Ingrid Freuze (Plateau ASTRAL, SFR Matrix, University of Angers) is gratefully acknowledged for MS characterization of the ligands and complexes. F.G. and B.L.G. thank the French GENCI/IDRIS-CINES center for high-performance computing resources and acknowledge the Stratégie d'Attractivité Durable (SAD18006-LnCPLSMM).

\section{REFERENCES}

(1) Kaur, M.; Choi, D. H. Diketopyrrolopyrrole: brilliant red pigment dye-based fluorescent probes and their applications. Chem. Soc. Rev. 2015, 44, 58-77.

(2) Yang, X.; Liu, X.; Li, Y.; Wu, F.; Mao, J.; Yuan, Y.; Cui, Y.; Sun, G.; Zhang, G. A differentially selective probe based on diketopyrrolopyrrole with fluorescence turn-on response to $\mathrm{Fe}^{3+}$, and dual-mode turn-on and ratiometric response to $\mathrm{Au}^{3+}$, and its application in living cell imaging. Biosensors and Bioelectronics 2016, $80,288-293$.

(3) Tsuto, K.; Nakamura, M.; Takada, T.; Yamana, K. Diketopyrrolopyrrole J-Aggregates Formed by SelfOrganization with DNA. Chem. Asian J. 2014, 9, 1618-1622.

(4) Wang, L.; Zhu, L.; Cao, D. A colorimetric probe based on diketopyrrolopyrrole and tert-butyl cyanoacetate for cyanide detection. New J. Chem. 2015, 39, 7211-7218.

(5) Chini, M. K.; Kumar, V.; Maiti, B.; De, P.; Satapathi, S. A dual "Turn-on/Turn-off" "FRET" sensor for highly sensitive and selective detection of lead and methylene blue based on fluorescent dansyl tagged copolymer and small molecule diketopyrrolopyrrole. Polymer Testing 2019, 79, 105997.

(6) Nielsen, C. B.; Turbiez, M.; McCulloch, I. Recent Advances in the Development of Semiconducting DPPContaining Polymers for Transistor Applications. Adv. Mater. 2013, 25, 1859-1880.

(7) Jin, Y.; Xu, Y.; Liu, Y.; Wang, L.; Jiang, H.; Li, X.; Cao, D. Synthesis of novel diketopyrrolopyrrole-based luminophores showing crystallization-induced emission enhancement properties. Dyes Pigm. 2011, 90, 311-318.

(8) Dhbaibi, K.; Favereau, L.; Srebro-Hooper, M.; Jean, M.; Vanthuyne, N.; Zinna, F.; Jamoussi, B.; Di Bari, L.; Autschbach, J.; Crassous, J. Exciton coupling in diketopyrrolopyrrole-helicene derivatives leads to red and near-infrared circularly polarized luminescence. Chem. Sci. 2018, 9, 735-742. 
(9) Qu, S.; Qin, C.; Islam, A.; Hua, J.; Chen, H.; Tian, H.; Han, L. Tuning the Electrical and Optical Properties of Diketopyrrolopyrrole Complexes for Panchromatic Dye-Sensitized Solar Cells. Chem. Asian J. 2012, 7, 28952903.

(10) Li, Y.; Sonar, P.; Murphy, L.; Hong, W. High mobility diketopyrrolopyrrole (DPP)-based organic semiconductor materials for organic thin film transistors and photovoltaics. Energy Environ. Sci. 2013, 6, 1684-1710.

(11) Komiyama, H.; Adachi, C.; Yasuda, T. Star-shaped and linear $\pi$-conjugated oligomers consisting of a tetrathienoanthracene core and multiple diketopyrrolopyrrole arms for organic solar cells. Beilstein J. Org. Chem. 2016, 12, 1459-1466.

(12) Chiminazzo, A.; Borsato, G.; Favero, A.; Fabbro, C.; McKenna, C. E.; Dalle Carbonare, L. G.; Valenti, M. T.; Fabris, F.; Scarso, A. Diketopyrrolopyrrole Bis-Phosphonate Conjugate: A New Fluorescent Probe for In Vitro Bone Imaging. Chem. Eur. J. 2019, 25, 3617-3626.

(13) Luňák Jr., S.; Vyňuchal, J.; Horáčková, P.; Frumarová, B.; Žák, Z.; Kučerík, J.; Salyk, O. Structure and Raman spectra of pyridyl substituted diketo-pyrrolo-pyrrole isomers and polymorphs. J. Mol. Struct. 2010, 983, 3947.

(14) Nie, K.; Dong, B.; Shi, H.; Liu, Z.; Liang, B. Diketopyrrolopyrrole Amphiphile-Based Micelle-Like Fluorescent Nanoparticles for Selective and Sensitive Detection of Mercury(II) Ions in Water. Anal. Chem. 2017, 89, 2928-2936.

(15) Pop, F.; Lewis, W.; Amabilino, D. B. Solid state supramolecular structure of diketopyrrolopyrrole chromophores: correlating stacking geometry with visible light absorption. CrystEngComm 2016, 18, 89338943.

(16) Nie, K.; Dong, B.; Shi, H.; Chao, L.; Duan, X.; Jiang, X.-F.; Liu, Z.; Liang, B. N-alkylated diketopyrrolopyrrolebased ratiometric/fluorescent probes for $\mathrm{Cu}^{2+}$ detection via radical process. Dyes Pigm. 2019, 160, 814-822.

(17) Langhals, H.; Limmert, M.; Lorenz, I.-P.; Mayer, P.; Piotrowski, H.; Polborn, K. Chromophores Encapsulated in Gold Complexes: DPP Dyes with Novel Properties. Eur. J. Inorg. Chem. 2000, 2345-2349.

(18) Lorenz, I.-P.; Limmert, M.; Mayer, P.; Piotrowski, H.; Langhals, H.; Poppe, M.; Polborn, K. DPP Dyes as Ligands in Transition-Metal Complexes. Chem. Eur. J. 2002, 8, 4047-4055.

(19) Kaim, W.; Lahiri, G. K. The coordination potential of indigo, anthraquinone and related redox-active dyes. Coord. Chem. Rev. 2019, 393, 1-8.

(20) Zhan, H.; Liu, Q.; So, S.-K.; Wong, W.-Y. Synthesis, characterization and photovoltaic properties of platinumcontaining poly(aryleneethynylene) polymers with electron-deficient diketopyrrolopyrrole unit. J. Organomet. Chem. 2019, 894, 1-9.

(21) Patil, Y.; Shinde, J.; Misra, R. Near-infrared absorbing metal functionalized diketopyrrolopyrroles. J. Organomet. Chem. 2017, 852, 48-53.

(22) Zhang, S.; Sun, T.; Xiao, D.; Yuan, F.; Li, T.; Wang, E.; Liu, H.; Niu, Q. A dual-responsive colorimetric and fluorescent chemosensor based on diketopyrrolopyrrole derivative for naked-eye detection of $\mathrm{Fe}^{3+}$ and its practical application. Spectrochim. Acta A 2018, 189, 594-600. 
(23) Hazari, A. S.; Mandal, A.; Beyer, K.; Paretzki, A.; Kaim, W.; Lahiri, G. K. Metal-Metal Bridging Using the DPPP Dye System: Electronic Configurations within Multiple Redox Series. Inorg. Chem. 2017, 56, 2992-3004.

(24) Yamagata, T.; Kuwabara, J.; Kanbara, T. Optical properties of highly planar diketopyrrolopyrrole derivatives fixed by coordinate bonds. Tetrahedron 2014, 70, 1451-1457.

(25) Hazari, A. S.; Ghosh, P.; Beyer, K.; Schwederski, B.; Kaim, W.; Lahiri, G. K. Effect of positional isomerism on the spectroelectrochemical response of 3,6-bis(2-pyridyl)-diketopyrrolopyrrolate bridged bis(carbonylhydridoruthenium) compounds. Dalton Trans. 2018, 47, 14078-14084.

(26) McCusker, C. E.; Hablot, D.; Ziessel, R.; Castellano, F. N. Metal Coordination Induced $\pi$-Extension and Triplet State Production in Diketopyrrolopyrrole Chromophores. Inorg. Chem. 2012, 51, 7957-7959.

(27) McCusker, C. E.; Hablot, D.; Ziessel, R.; Castellano, F. N. Triplet State Formation in Homo- and Heterometallic Diketopyrrolopyrrole Chromophores. Inorg. Chem. 2014, 53, 12564-12571.

(28) Goswami, S.; Winkel, R. W.; Alarousu, E.; Ghiviriga, I.; Mohammed, O. F.; Schanze, K. S. Photophysics of Organometallic Platinum(II) Derivatives of the Diketopyrrolopyrrole Chromophore. J. Phys. Chem. A 2014, $118,11735-11743$.

(29) Goswami, S.; Hernandez, J. L.; Gish, M. K.; Wang, J.; Kim, B.; Laudari, A. P.; Guha, S.; Papanikolas, J. M.; Reynolds, J. R.; Schanze, K. S. Cyclometalated Platinum-Containing Diketopyrrolopyrrole Complexes and Polymers: Photophysics and Photovoltaic Applications. Chem. Mater. 2017, 29, 8449-8461.

(30) Constable, E. C.; Henney, R. P. G.; Raithby, P. R.; Sousa, L. R. Metal-Ion Dependent Regioselectivity in Cyclometalation Reactions. Angew. Chem. Int. Ed. Engl. 1991, 30, 1363-1364.

(31) Constable, E. C.; Henney, R. P. G.; Raithby, P. R.; Sousa, L Cyclometallation Reactions of 6-(2-Thienyl)-2,2'bipyridine with $d^{8}$ Transition Metal lons. J. Chem. Soc. Dalton Trans 1992, 2251-2258.

(32) Lu, W.; Mi, B.-X.; Chan, M. C. W.; Hui, Z.; Che, C.-M.; Zhu, N.; Lee, S.-T. Light-Emitting Tridentate Cyclometalated Platinum(II) Complexes Containing $\sigma$-Alkynyl Auxiliaries: Tuning of Photo- and Electrophosphorescence. J. Am. Chem. Soc. 2004, 126, 4958-4971.

(33) Lu, W.; Chan, M. C. W.; Zhu, N.; Che, C.-M.; Li, C.; Hui, Z. Structural and Spectroscopic Studies on Pt...Pt and $\pi-\pi$ Interactions in Luminescent Multinuclear Cyclometalated Platinum(II) Homologues Tethered by Oligophosphine Auxiliaries. J. Am. Chem. Soc. 2004, 126, 7639-7651.

(34) Wu, P.; Wong, E. L.-M.; Ma, D.-L.; Tong, G. S. M.; Ng, K.-M.; Che, C.-M. Cyclometalated Platinum(II) Complexes as Highly Sensitive Luminescent Switch-On Probes for Practical Application in Protein Staining and Cell Imaging. Chem. Eur. J. 2009, 15, 3652-3656.

(35) Chow, P.-K.; Cheng, G.; Tong, G. S. M.; To, W.-P.; Kwong, W.-L.; Low, K.-H.; Kwok, C.-C.; Ma, C.; Che, C.-M. Luminescent Pincer Platinum(II) Complexes with Emission Quantum Yields up to Almost Unity: Photophysics, Photoreductive C-C Bond Formation, and Materials Applications. Angew. Chem. Int. Ed. 2015, 54, 2084-2089.

(36) Kui, S. C. F.; Chow, P.-K.; Tong, G. S. M.; Lai, S.-L.; Cheng, G.; Kwok, C.-C.; Low, K.-H.; Ko, M. Y.; Che, C.-M. Robust Phosphorescent Platinum(II) Complexes Containing Tetradentate $\mathrm{O}^{\wedge} \mathrm{N}^{\wedge} \mathrm{C}^{\wedge} \mathrm{N}$ Ligands: Excimeric Excited State and Application in Organic White-Light-Emitting Diodes. Chem. Eur. J. 2013, 16, 69-73. 
(37) Cheng, G.; Chow, P.-K.; Kui, S. C. F.; Kwok, C.-C.; Che, C.-M. High-Efficiency Polymer Light-Emitting Devices with Robust Phosphorescent Platinum(II) Emitters Containing Tetradentate Dianionic $\mathrm{O}^{\wedge} \mathrm{N}^{\wedge} \mathrm{C}^{\wedge} \mathrm{N}$ Ligands. Adv. Mater. 2013, 25, 6765-6770.

(38) Cocco, F.; Zucca, A.; Stoccoro, S.; Serratrice, M.; Guerri, A.; Cinellu, M. A. Synthesis and Characterization of Palladium(II) and Platinum(II) Adducts and Cyclometalated Complexes of 6,6-Dimethoxy-2,2-bipyridine: $\mathrm{C}\left(\mathrm{sp}^{3}\right)-\mathrm{H}$ and $\mathrm{C}\left(\mathrm{sp}^{2}\right)-\mathrm{H}$ Bond Activations. Organometallics 2014, 33, 3414-3424.

(39) Liu, S.-Y.; Shi, M.-M.; Huang, J.-C.; Jin, Z.-N.; Hu, X.-L.; Pan, J.-Y.; Li, H.-Y.; Jen, A. K.-Y.; Chen, H.-Z. C-H Activation: Making Diketopyrrolopyrrole Derivatives Easily Accessible. J. Mater. Chem. A 2013, 1, 27952805.

(40) Lin, Y.-Y.; Chan, S.-C.; Chan, M. C. W.; Hou, Y.-J.; Zhu, N.; Che, C.-M.; Liu, Y.; Wang, Y. Structural, Photophysical, and Electrophosphorescent Properties of Platinum(II) Complexes Supported by Tetradentate $\mathrm{N}_{2} \mathrm{O}_{2}$ Chelates. Chem. Eur. J. 2003, 9, 1263-1272.

(41) Kwok, C.-C.; Ngai, H. M. Y.; Chan, S.-C.; Sham, I. H. T.; Che, C.-M.; Zhu, N. [(O^N^N)PtX] Complexes as a New Class of Light-Emitting Materials for Electrophosphorescent Devices. Inorg. Chem. 2005, 44, 4442-4444.

(42) Domokos, A.; Aronow, S. D.; Tang, T.; Shevchenko, N. E.; Tantillo, D. J.; Dudnik, A. S. Synthesis and Optoelectronic Properties of New Methoxy-Substituted Diketopyrrolopyrrole Polymers. ACS Omega 2019, 4, 9427-9433.

(43) Herberger, J; Winter, R. F. Platinum emitters with dye-based $\sigma$-aryl ligands. Coord. Chem. Rev. 2019, 400, 213048.

(44) Kirkus, M.; Wang, L.; Mothy, S.; Beljonne, D.; Cornil, J.; Janssen, R. A. J.; Meskers, S. C. J. Optical Properties of Oligothiophene Substituted Diketopyrrolopyrrole Derivatives in the Solid Phase: Joint J- and H-Type Aggregation. J. Phys. Chem. A 2012, 116, 7927-7936.

(45) Lucarelli, J.; Lessi, M.; Manzini, C.; Minei, P.; Bellina, F.; Pucci, A. N-alkyl diketopyrrolopyrrole-based fluorophores for luminescent solar concentrators: Effect of the alkyl chain on dye efficiency. Dyes Pigm. 2016, 135, 154-162.

(46) Pop, F.; Humphreys, J.; Schwartz, J.; Brown, L.; van der Berg, A.; Amabilino, D. B. Towards more sustainable synthesis of diketopyrrolopyrroles. New J. Chem. 2019, 43, 5783-5790. 


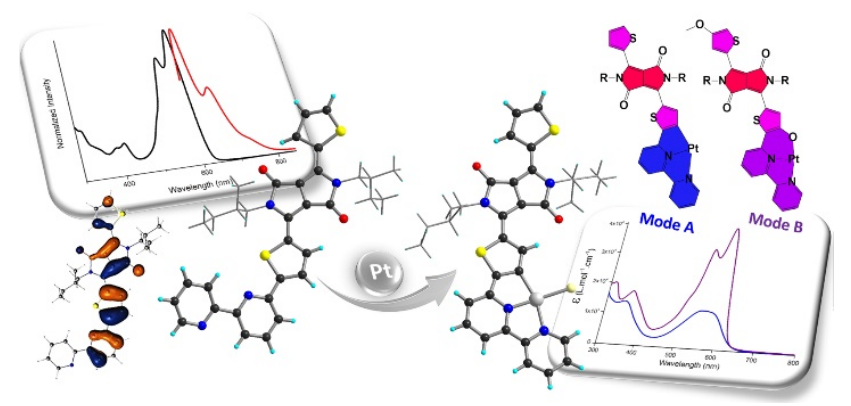

Unprecedented diketopyrrolopyrrole-thiophene-2,2'-bipyridine (DPPT-bpy) ligands together with platinum(II) complexes are described and their photophysical properties investigated. 